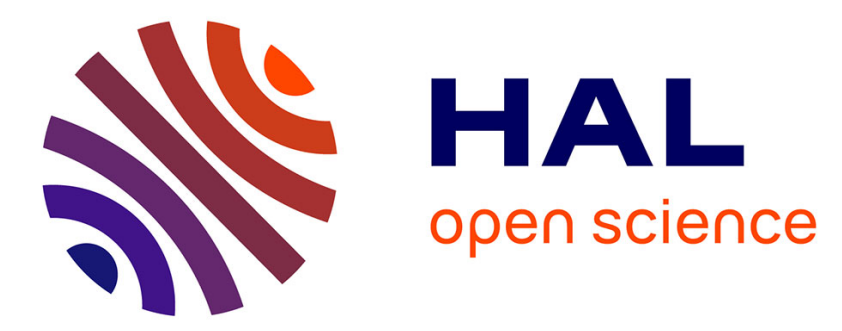

\title{
Le silex bédoulien sur les sites chasséens du Languedoc: étude fonctionnelle, statut des sites et réseaux de diffusion
}

\author{
Loïc Torchy, Bernard Gassin
}

\section{To cite this version:}

Loïc Torchy, Bernard Gassin. Le silex bédoulien sur les sites chasséens du Languedoc: étude fonctionnelle, statut des sites et réseaux de diffusion. Gallia Préhistoire - Préhistoire de la France dans son contexte européen, 2011, 53, pp.59-84. 10.3406/galip.2011.2487 . hal-02343284

\section{HAL Id: hal-02343284 \\ https://hal.science/hal-02343284}

Submitted on 19 Dec 2019

HAL is a multi-disciplinary open access archive for the deposit and dissemination of scientific research documents, whether they are published or not. The documents may come from teaching and research institutions in France or abroad, or from public or private research centers.
L'archive ouverte pluridisciplinaire HAL, est destinée au dépôt et à la diffusion de documents scientifiques de niveau recherche, publiés ou non, émanant des établissements d'enseignement et de recherche français ou étrangers, des laboratoires publics ou privés.

\section{(ㅇ)(1) $\$$}

Distributed under a Creative Commons Attribution - NonCommercial - NoDerivatives $\mid 4.0$ 


\title{
LE SILEX BÉDOULIEN \\ SUR LES SITES CHASSÉENS \\ DU LANGUEDOC: ETUDE \\ FONCTIONNELLE, STATUT DES \\ SITES ET RESEAUX DE DIFFUSION
}

\author{
Loïc TORCHY* et Bernard GASSIN **
}

\begin{abstract}
Mots-clés. Néolithique moyen, Chasséen méridional, tracéologie, fonction des outils, spécialisation artisanale, système technique. Résumé. Notre étude porte sur la gestion des productions lithiques en silex bédoulien sur des sites chasséens languedociens importateurs et consommateurs compris dans l'aire de diffusion massive et relativement proches les uns des autres, mais éloignés des ateliers producteurs. Il s'agit des sites du Pirou à Valros (Hérault), de Langel à Armissan (Aude) et du fossé St2 d'Auriac à Carcassonne (Aude). Des différences de gestion ont été observées entre les différentes productions (avec ou sans traitement thermique; entre lames/lamelles/ éclats; entre différents rythmes de débitage), mais aussi entre les différents sites. Les sous-systèmes techniques de la coupe des végétaux, du travail de la peau, de l'os et de la céramique ont pu être discutés en abordant la question de la spécialisation artisanale. Différents statuts de sites ont pu être mis en évidence grâce à la représentation des différentes classes fonctionnelles. La forte représentation de la coupe de végétaux sur les sites du Pirou et de Langel leur confère une vocation agricole, tandis que le spectre fonctionnel d'Auriac révèle un statut bien différent des deux autres. L'analyse fonctionnelle a introduit quelques pistes de réflexion confortant l'hypothèse d'un site redistributeur de lamelles débitées par pression après traitement thermique. Enfin, la complexité des réseaux de diffusion des silex bédouliens a été abordée par la mise en évidence d'une variabilité d'aisance d'approvisionnement révélant différents degrés d'intégration dans ces réseaux.
\end{abstract}

Key-words. Middle Neolithic, Chassey Culture, Bedoulian flint, exchange systems, use-wear analysis, tool use, site status, craft specialization, systèmes techniques.

Abstract. Our study focuses on the management of Bedoulian flint productions in the Chassey Culture, on importer and consumer sites in Languedoc, which are in the zone of mass diffusion and relatively close to each other, but far from workshop producer site. These sites are Le Pirou in Valros (Hérault), Armissan in Langel (Aude) and Auriac in Carcassonne (Aude). Management differences were observed between the different productions (with or without heat treatment; between blades/bladelets/flakes and between different rhythms of knapping) and between different sites. The sous-systèmes techniques of plant cutting, skin, bone and ceramic working are discussed by addressing the issue of craft specialization. Different site statuses are identified through the representation of different functional classes. The strong representation of plant cutting at Le Pirou and Langel shows them to be related to agriculture, while the functional spectrum of Auriac reveals a very different status from the two others. The functional analysis introduced some ideas supporting the hypothesis of bladelets (knapped by pressure after heat treatment) redistribution site. Finally, the complexity of the diffusion of Bedoulian flint is approached through a demonstration of supply ease variability, revealing different levels of integration in exchanges systems.

* Université de Toulouse-Le Mirail, TRACES, UMR 5608 du CNRS/CEMES-UPR 8011 du CNRS, Maison de la recherche, 5 allées AntonioMachado, F-31058 Toulouse Cedex 9. Courriel: 1.torchy@laposte.net

** Université de Nice Sophia Antipolis, CEPAM, UMR 6130 du CNRS-UNS, Campus Saint-Jean-d’Angély, 24 avenue des Diables Bleus, F-06300 Nice. Courriel: bernard.gassin@ac-nice.fr 


\section{INTRODUCTION}

Entre la fin du $V^{e}$ et le premier tiers du IV millénaire, la diffusion de produits lithiques en quantités importantes et sur de longues distances (Binder, Perlès et al., 1990; Perlès, 2007) prend une grande ampleur dans le Midi méditerranéen. Le silex bédoulien, extrait des affleurements du Crétacé inférieur du nord du Vaucluse, est retrouvé sur tous les sites chasséens du sud de la France (Binder, 1991) et, même au-delà, dans d'autres cultures en Catalogne, Suisse et nord de l'Italie (Léa, 2005).

L'étude des chaînes opératoires, segmentées dans l'espace et dans le temps, a permis d'appréhender l'organisation complexe de ces sociétés, par la mise en évidence de savoir-faire non partagés, comme la volonté de créer artificiellement une nouvelle matière première par un recours au traitement thermique (Binder, Perlès et al.,1990) ou comme la délicate phase de mise en forme des blocs, toutes deux réalisées uniquement dans la zone des ateliers producteurs vauclusiens (Léa, 2004c). La diffusion vers les sites consommateurs se fait, pour toute la durée du Chasséen, sous la forme de produits finis (lames et éclats) pour le silex bédoulien non chauffé, et à partir de 4100 av. J.-C. environ (Léa, Gassin, Briois, 2004), sous la forme de nucléus chauffés et préformés selon différents modes, en vue d'un débitage de lamelles par pression (Binder, 1984 et 1991 ; Léa et al., 2007). Ces productions sont opposées à des productions non spécialisées, qui peuvent être issues des matières premières locales, mais aussi sur silex bédoulien (Léa, 2004b; Gassin, Léa, 2006).

Les études tracéologiques réalisées sur silex bédoulien ont montré qu'il existait des différences de gestion, entre le silex chauffé et non chauffé (Binder, Gassin, 1988; Gassin, 1996), entre lamelles de différents codes opératoires (Binder, Gassin, 1988), entre sites producteurs et sites consommateurs (Gassin, Léa et al., 2006), et enfin, entre sites chasséens et sites des cultures voisines (Sepulcres de fosa, Monbolo) qui ont aussi été approvisionnés en silex bédoulien (Gibaja Bao, 2003; Gassin, Astruc et al., 2006; Gassin et al., 2010; Astruc, Léa, sous presse).

Nous nous sommes interrogés sur les modalités de gestion du silex bédoulien dans une zone éloignée des ateliers producteurs mais comprise dans l'aire de diffusion massive (Gassin et al., 2010). Pour cela, trois sites languedociens relativement peu éloignés les uns des autres ont fait l'objet d'une étude tracéologique (Torchy, 2009). Deux axes de recherche principaux ont été suivis. Est-il possible de mettre en évidence des différences de gestion selon les types de

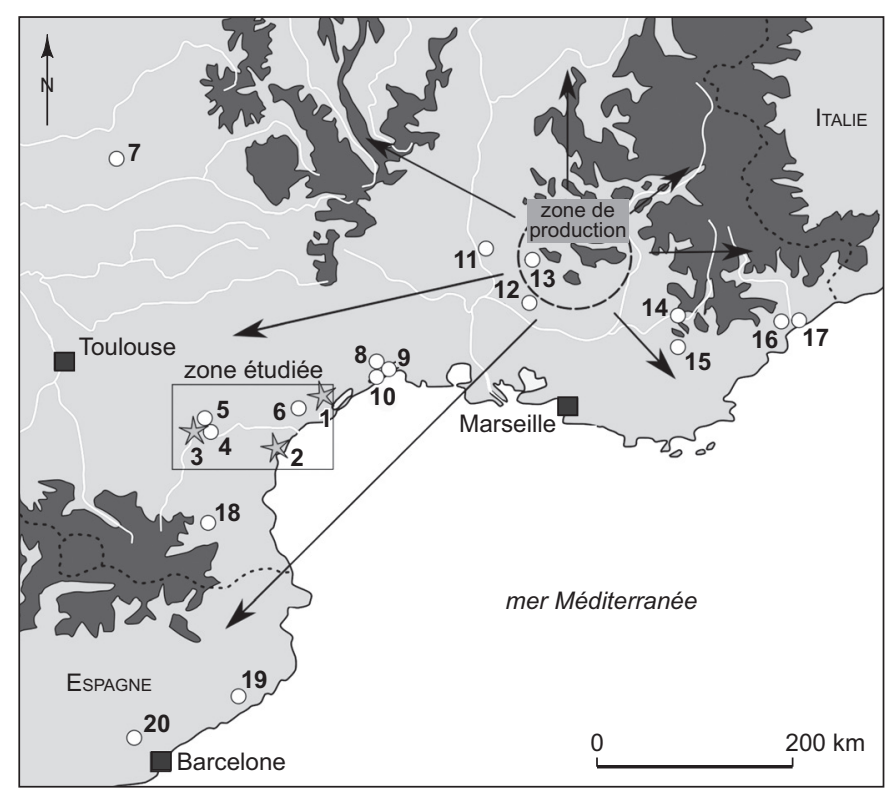

$\varkappa$ site étudié en Languedoc $\bigcirc$ site mentionné dans le texte pour comparaison

Fig. 1 - Zone de production, diffusion du silex bédoulien (d'après Léa, 2005) et sites mentionnés dans le texte. 1, Le Pirou;

2, Langel; 3, Auriac; 4, Les Plots; 5, Font-Juvénal; 6, Le Crès;

7, Roucadour; 8, Jacques-Cour; 9, Lattes; 10, Port-Ariane;

11, Rocalibert; 12, Claparouse; 13, La Combe; 14, L'Église supérieure; 15, Fontbrégoua; 16, Chiris; 17, Giribaldi; 18, Montou; 19, Can Grau; 20, Bòbila Madurell (DAO: L. Torchy).

productions identifiées sur silex bédoulien ? Constate-t-on une différence de gestion entre les différents sites étudiés? Cette problématique se déclinant différemment selon les sites envisagés, des questionnements relatifs à chaque site sont exposés plus bas.

\section{PRÉSENTATION DU CORPUS ET MÉTHODE D’ÉTUDE}

Le corpus étudié comprend trois sites de plein air languedociens (fig. 1) sur lesquels les productions sont variées (tabl. I).

\section{LE PIROU (VALROS, HÉRAULT)}

La première évocation d'un site néolithique au lieu-dit le Pirou a été publiée en 1950 dans le Bulletin de la société archéologique de Béziers (Serres, 1950). En 1997, le projet de réalisation du dernier tronçon autoroutier de l'A75 entre Béziers et Pézenas a conduit à une importante enquête 
Tabl. I - Comparaison des productions observées sur chaque site (la présence de chaque production est matérialisée par une croix).

\begin{tabular}{|c|c|c|c|c|}
\hline MP & Production Site & Le Pirou & Langel & Auriac \\
\hline \multirow{4}{*}{ 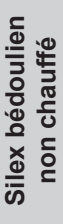 } & lames importées & & & \\
\hline & lamelles importées & & & \\
\hline & éclats importés & & & \\
\hline & éclats débités sur place & & & \\
\hline \multirow{4}{*}{ 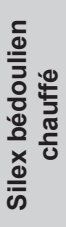 } & lamelles importées & & & ? \\
\hline & lamelles débitées sur place & & & \\
\hline & éclats importés & & & ? \\
\hline & éclats débités sur place & & & \\
\hline
\end{tabular}

archéologique à la demande du Service régional de l'archéologie, lors de laquelle onze secteurs d'intervention ont été sondés (Kotarba, 1998; Kotarba et al., 1998). Sur la future aire de service de Tourbes-Valros, les locus 1 et 2 du secteur 3 ont fait l'objet d'une fouille de sauvetage dirigée par G. Loison du 20 octobre 2006 au 15 juin 2007. Ces fouilles ont révélé plus de 300 fosses ayant servi pour la plupart de structures de stockage sur une surface de 2,5 hectares. Le mobilier lithique est représenté par 3841 éléments, dont plus de $70 \%$ de quartz. La quasi-totalité du silex bédoulien, qui représente environ $15 \%$ de l'effectif total de l'assemblage, est non chauffée (Torchy, 2008), ce qui a permis de confirmer l'attribution au Chasséen ancien, qui avait été proposée lors de la fouille au regard de la céramique. Concernant le silex bédoulien, l'introduction de lames non chauffées probablement débitées par percussion indirecte dans la zone des ateliers producteurs vauclusiens contraste avec une production domestique de petits éclats à partir de gros éclats importés non chauffés. Les grattoirs et les pièces esquillées représentent la majorité des supports transformés, comme cela a déjà été observé sur les sites chasséens anciens du Crès à Béziers (Léa, 2004b), de Port-Ariane à Lattes (Léa, 2004b et 2007) et des Plots à Berriac (Briois, 2005). L'étude tracéologique concerne 98 pièces (soit $18 \%$ du silex bédoulien) qui sont sélectionnées de manière à retenir la totalité des lames, environ la moitié des grattoirs et perçoirs, et une partie des petits éclats, dans le but de répondre aux questions suivantes. Pour quel besoin a-t-on produit des petits éclats sur place à partir de gros éclats importés ? Peut-on observer une différence de gestion entre les productions spécialisées importées et les productions domestiques peu investies?

\section{LANGEL (ARMISSAN, AUDE)}

Le gisement fut découvert en 1919 par T. et P. Helena qui effectuèrent plusieurs prospections révélant essentiellement du mobilier lithique. En 1969, une fouille dirigée par J. Guilaine a mis en évidence une aire de galets subcirculaire contenue dans une fosse d'une profondeur de 20 à $30 \mathrm{~cm}$ (Guilaine, 1970). Des restes de faune, de céramique et d'industrie lithique ont été découverts en surface de cette structure qui a pu être attribuée au Chasséen ancien (entre 4300 et 4000 av. J.-C.). Le mobilier lithique est représenté par 395 éléments, dont 312 en silex bédoulien, 20 en quartz et 27 en silex tertiaire local (Briois, 2005). De nombreuses lames en silex bédoulien non chauffé ont été importées sur le site. Un débitage sur place d'éclats en silex bédoulien est attesté par la présence de nucléus. Deux lamelles en silex bédoulien chauffé ont été introduites sur le site sous forme de produits finis. D'un point de vue typologique, les extrémités appointies, les grattoirs et les pièces esquillées sont les plus représentés, suivis des burins et armatures de flèches.

La sélection destinée à l'étude tracéologique comprend 36 pièces (soit $12 \%$ du silex bédoulien) en respectant les proportions de lames et d'éclats afin de répondre aux questions suivantes. Comme pour le site du Pirou, peut-on observer une différence de gestion entre productions importées et productions domestiques? Les mêmes productions sont-elles gérées de la même manière sur les deux sites?

\section{AURIAC (GARGASSONNE, AUDE)}

Le site fut découvert lors d'une prospection pédestre par M.-L. Durand en 1966. Des sondages ont été réalisés par J. Guilaine et son équipe en 1971 et 1972. Le projet d'aménagement d'un golf fut à l'origine de nouveaux sondages et de fouilles de sauvetage entre 1985 et 1988 (Vaquer, 1990). Les études concernant l'industrie céramique ont permis d'attribuer le site à la fin du Chasséen classique (Vaquer, 1990 ; Jédikian, 1998), c'est-à-dire vers 3500 av. J.-C.

Situé loin des gîtes du Vaucluse, ce site est l'un des plus importants du point de vue des effectifs de silex bédouliens. À partir de modèles théoriques (Renfrew, 1984) et devant la très forte proportion de lamelles en silex bédoulien chauffé, l'hypothèse de site redistributeur a été proposée pour Auriac (Vaquer, 1991; Vaquer, Remicourt, 2010). 
Le fossé ST2 est à lui seul riche de 676 éléments lithiques, dont 611 en silex bédoulien chauffé (plus de $90 \%$ ), seulement 9 en silex bédoulien non chauffé (1,3\%), 20 en silex tertiaire local, 13 en quartz, et un élément en obsidienne. Des préformes en silex bédoulien traité thermiquement ont été introduites sur le site puis débitées par pression à la béquille pour l'obtention des lamelles. Environ $25 \%$ de ces lamelles ont été transformées, par des retouches irrégulières ou en burins dans la plupart des cas (Remicourt, 2004).

L'étude tracéologique porte sur une sélection de 56 pièces (soit $9 \%$ du silex bédoulien) qui inclut la totalité du silex bédoulien non chauffé (9 pièces), et une partie du silex traité thermiquement en respectant les proportions de lamelles de chaque code opératoire, afin de répondre à ces questions: observe-t-on une différence de gestion entre les lamelles chauffées et non chauffées ? Les lamelles de différents codes opératoires ont-elles fait l'objet de gestions différentes ? D’un point de vue général, les produits sont-ils gérés de la même manière que pour les deux sites attribués au Chasséen ancien?

\section{MÉTHODE D'ÉTUDE}

Un historique des méthodes et des recherches en tracéologie a très récemment été publié (Claud, 2008) et il semble inutile d'en faire l'exposé. Il s'agit de rappeler ici que la méthode d'étude est basée sur l'observation des traces d'utilisation à faible et à fort grossissement (loupe binoculaire et microscope optique métallographique), c'est-à-dire de 10x à $200 x$, et quelquefois à 400x, et une interprétation par analogie à partir de plusieurs corpus expérimentaux et par des critères d'inférence déduits de ces données expérimentales (González Urquijo, Ibáñez Estevez, 1994; Gassin, 1996).

Les éléments lithiques du Pirou et de Langel présentent une forte «patine» blanche souvent considérée comme étant incompatible avec une étude tracéologique. L'état de conservation des traces dépend de plusieurs facteurs physico-chimiques et de la micro-morphologie des polis (Plisson, 1985).

Pour cette analyse, l'aspect blanchâtre n'a pas été un critère de sélection des pièces. En toute logique, la «patine» blanche ne pose aucun problème pour l'observation des micro-écaillements et des émoussés. Concernant les polis, il faut noter qu'ils sont assez altérés dans le cas de Langel, et en revanche, relativement bien conservés sur les éléments lithiques du Pirou. Les surfaces blanches réfléchissent la lumière et l'observation au microscope est rendue plus délicate. L'inclinaison de la pièce jouant ici un rôle prépondérant sur la qualité de l'image, l'observation à la loupe binoculaire a été prolongée afin de cibler les zones d'observation au microscope.

\section{FONCTIONS ET FONCTIONNEMENTS DES OUTILS}

\section{LE PIROU À VALROS}

\section{LA COUPE DE VÉGÉTAUX TENDRES}

Vingt outils (14 lames et 6 éclats), correspondant à 30 zones d'utilisation, ont coupé des végétaux tendres. La variabilité des traces observées a permis de les classer en cinq groupes.

Une lame utilisée sur un bord (fig. 2, no 1538) présente un poli brillant et visible à l'œil nu, parallèle au bord et d'extension couvrante. L'observation au microscope révèle une trame compacte lisse et des stries longitudinales (fig. 3). Les caractères de ces traces sont directement comparables
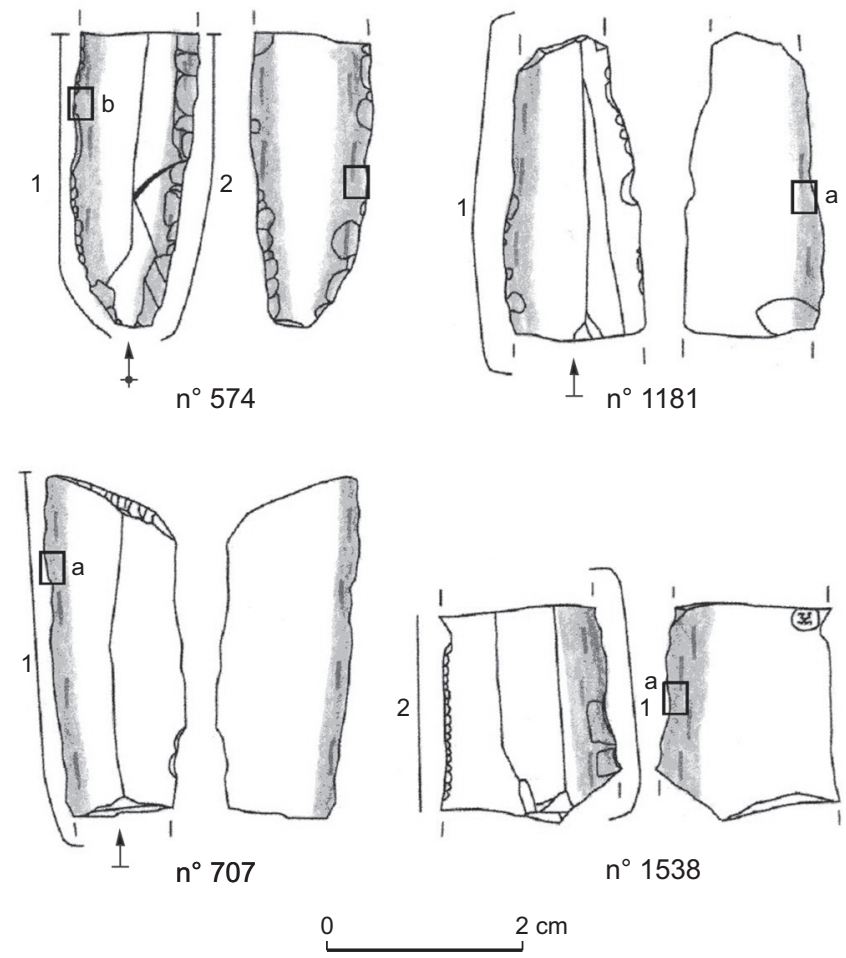

Fig. 2 - Le Pirou: fragments de lames nos 574, 1181 et 1538 et lame tronquée $n^{0} 707$ (silex bédoulien non chauffé). La trame grise matérialise l'extension des polis visibles à l'œil nu (dessin: L. Torchy). 


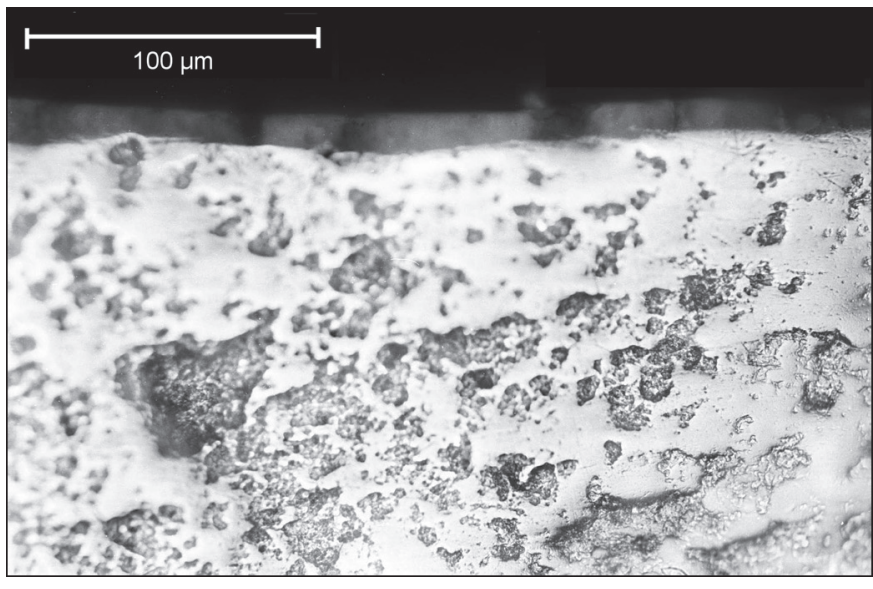

Fig. 3 - Le Pirou: poli compact lisse sur lame $n^{\circ} 1538$ (photo prise en a fig. 2, 200x; cliché: L. Torchy).

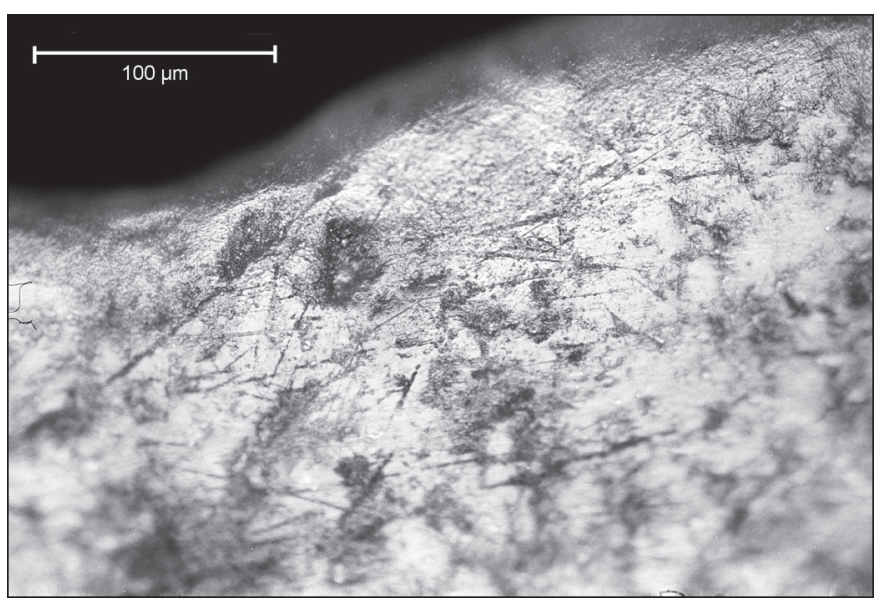

Fig. 4 - Le Pirou: association de poli lisse et de poli grenu et stries larges sur lame $n^{0} 707$ (photo prise en a fig. 2, 200x; cliché: L. Torchy).

aux pièces expérimentales utilisées pour la moisson de céréales, ou pour la coupe d'autres végétaux non ligneux. En contexte chasséen, l'hypothèse de la moisson reste la plus probable, même si la coupe de végétaux peut avoir d'autres intérêts (Gassin, 1996).

Une lame utilisée sur un bord, (fig. 2, no 707), présente un poli compact lisse associé à un poli grenu situé sur l'émoussé du fil actif et d'extension transversale modérée (fig. 4). Ce type d'association de trames se retrouve expérimentalement sur des pièces ayant servi à couper de la paille à même le sol (Gibaja Bao, 2003; Ibáñez Estevez et al., 2008), les contacts de l'outil avec la terre engendrant un poli grenu.

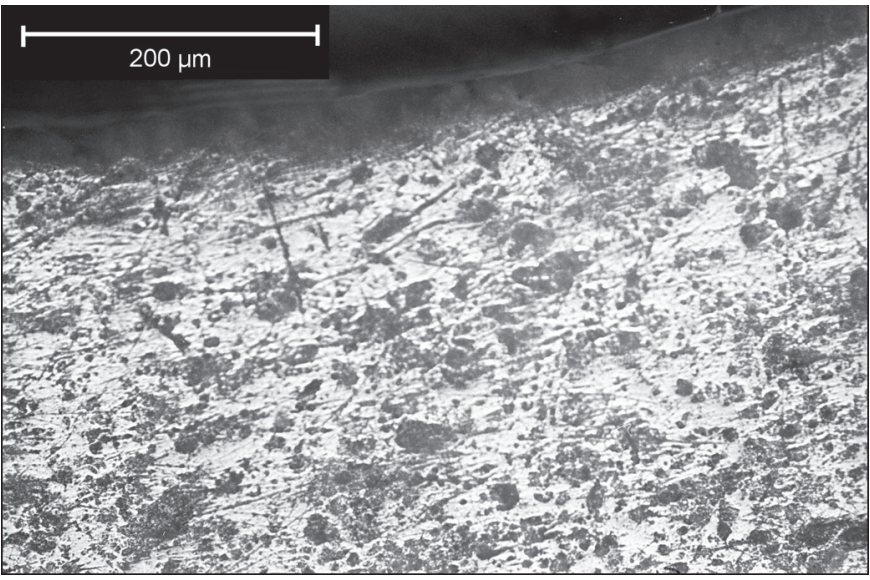

Fig. 5 - Le Pirou: poli avec stries et «comètes » sur lame $n^{0} 574$ (photo prise en b fig. 2, 100x; cliché: L. Torchy).

Les traces observées sur la lame $n^{\circ} 574$ (fig. 5), fort émoussé, poli brillant et visible à l'œil nu, parallèle aux bords, d'extension couvrante avec nombreuses stries et arrachements de poli en forme de «comètes", présentent de fortes similitudes avec des lames ayant été insérées sur un tribulum, par comparaison avec des expérimentations et des données ethnographiques et historiques (Anderson, Chabot, Van Gijn, 2004; Anderson, Chabot, 2004; Anderson et al., 2006). Ce type d'outil agricole, fréquent au Proche-Orient du Néolithique récent au Bronze ancien, n'est jusqu'à présent pas attesté de façon sûre dans le Néolithique d'Europe occidentale. En contexte chasséen, des phytolithes retrouvés sur le site de Claparouse à Lagnes (Vaucluse) présentent les caractères d'une coupe au tribulum (Verdin dans Léa et al., 2003). Le fait que l'on ne retrouve jamais ce type de lame en grande quantité est cependant gênant pour imaginer l'emploi de tribulum au Chasséen. Il faudrait peut-être imaginer d'autres outils agricoles, de dimensions plus modestes, et dont les parties actives auraient eu le même fonctionnement.

Sept lames (fig. 2, $\mathrm{n}^{\mathrm{o}} 1181$ ) et trois éclats (fig. 6, $\mathrm{n}^{\text {os }} 212$ et 700) présentent des polis parallèles aux bords, d'extension couvrante, à trame semi-serrée à ouverte en s'éloignant du bord (fig. 7). Le fait que seules les parties les plus élevées de la microtopographie soient affectées par le poli semble indiquer un travail sur une matière végétale plutôt dure comme le bois (fig. 8), mais cela entre en contradiction avec le fait que le bord est souvent resté brut avec peu d'enlèvements, et l'extension couvrante du poli suggère un travail sur une matière végétale plutôt tendre. Après observation d'un bon nombre de pièces expérimentales, 

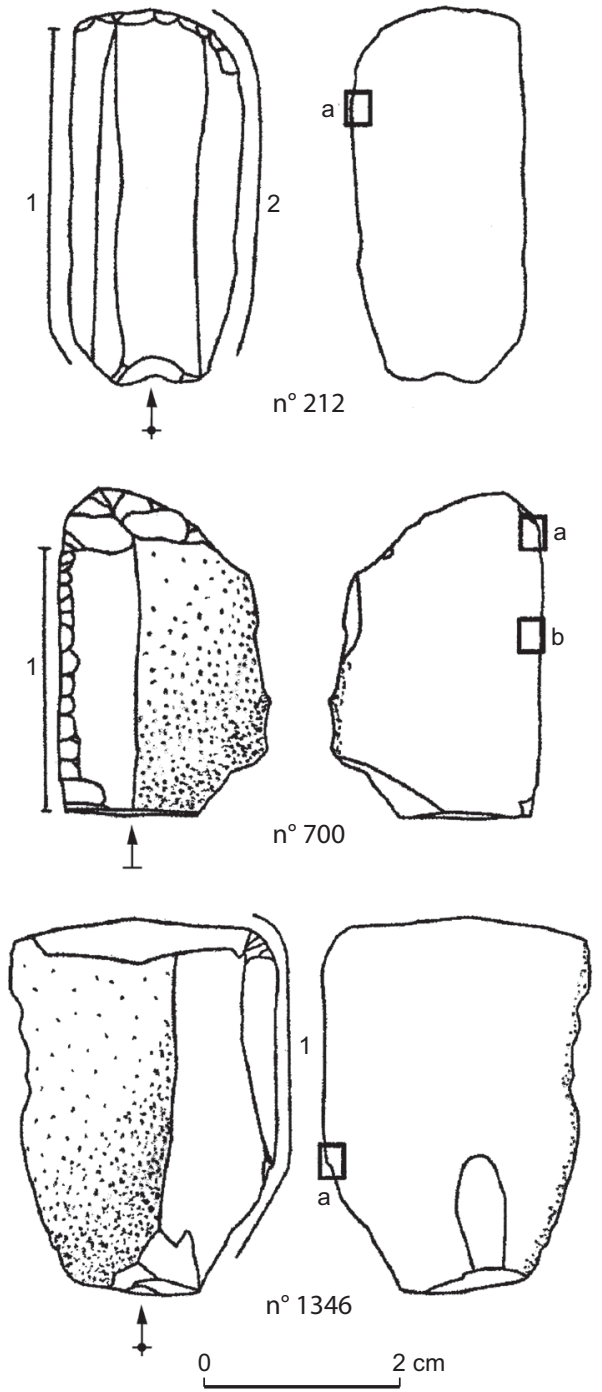

Fig. 6 - Le Pirou: lame tronquée $n^{0}$ 212, fragment d'éclat cortical à retouches directes latérales et distales $n^{\circ} 700$ et éclat cortical rebroussé $n^{0} 1346$ (silex bédoulien non chauffé) (dessin: L. Torchy).

il s'avère que de nombreuses pièces présentent les mêmes caractéristiques, après un travail de courte durée (entre une demi-heure et une heure) pour la moisson de céréales.

Sur trois lames et trois éclats (fig. $6, \mathrm{n}^{\circ}$ 1346), le poli a un aspect grenu (fig. 9), et une extension transversale couvrante avec de nombreuses stries parallèles, et quelquefois des lambeaux de poli à trame compacte et lisse. Deux hypothèses sont envisagées. D'une part, il pourrait s'agir d'un phénomène d'altération, le poli aurait été modifié par le temps et le contexte d'enfouissement (Plisson, 1985 et 1986; Plisson, Mauger, 1988). D'autre part, des contacts

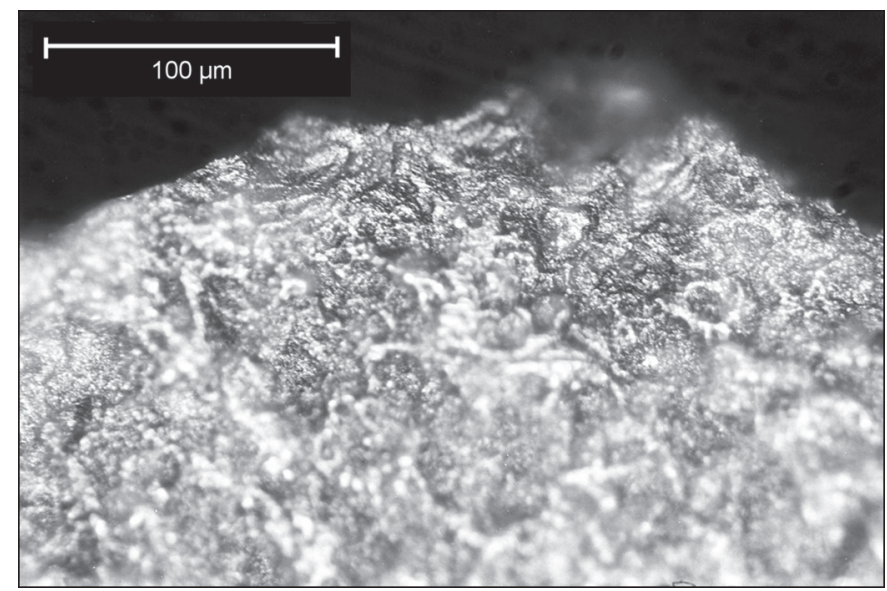

Fig. 7 - Le Pirou: poli à trame semi-serrée à ouverte sur éclat $n^{0} 700$ (photo prise en a fig. 6, 200x; L. Torchy).

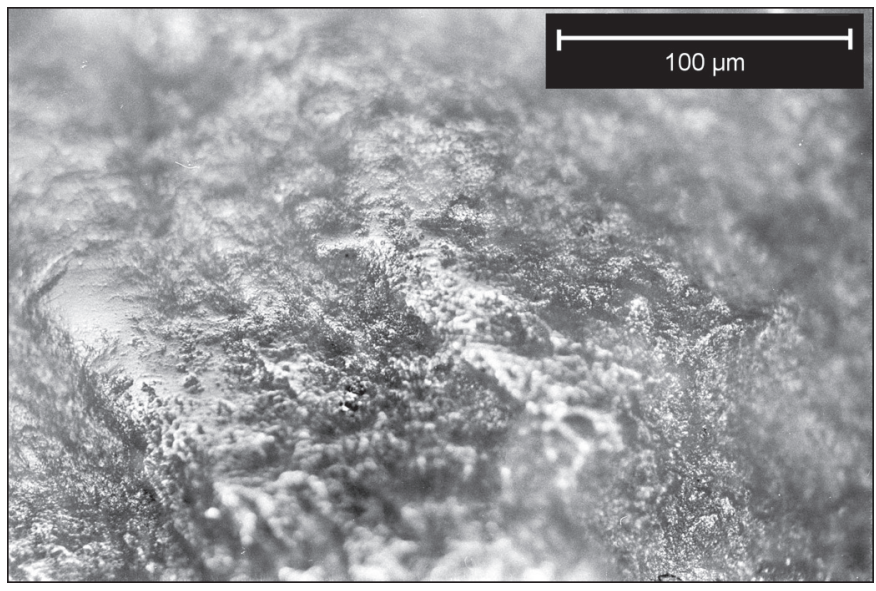

Fig. 8 - Le Pirou: poli qui affecte les parties les plus élevées sur lame $n^{o} 1181$ (photo prise en a fig.2, 200x; cliché: L. Torchy).

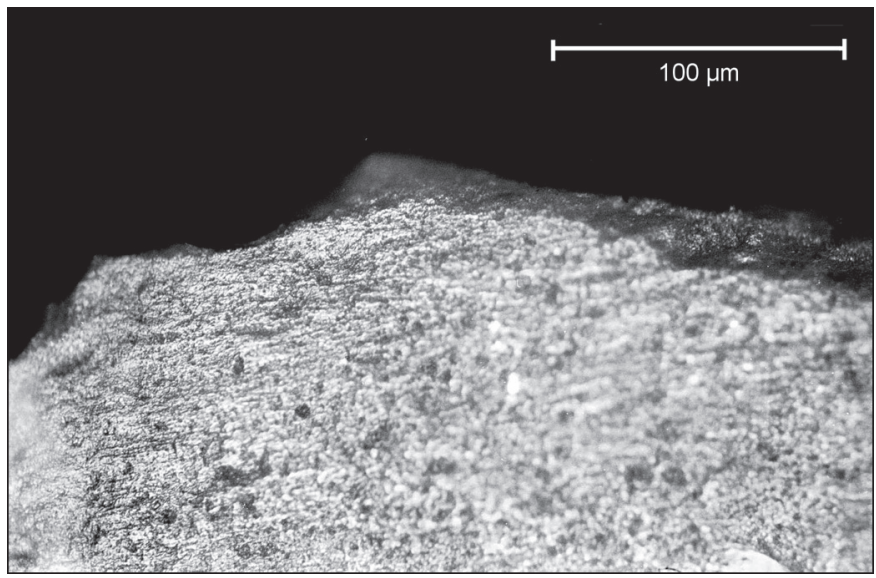

Fig. 9 - Le Pirou: poli sur l'éclat no 1346 (photo prise en a fig. 6, 200x; cliché: L. Torchy). 


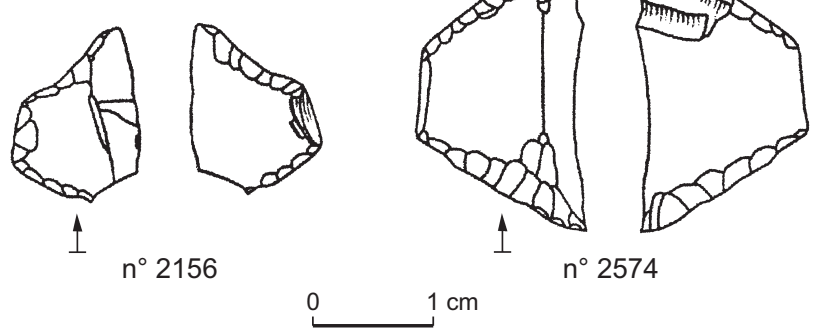

Fig. 10 - Le Pirou: armatures trapézoïdales sur éclats $n^{o s} 2156$ et 2574 (silex bédoulien non chauffé). Les enlèvements ombragés sont dus aux impacts (dessin: L. Torchy).

avec des matières minérales, pendant la coupe de végétaux ou lors d'une réutilisation, auraient pu modifier l'aspect du poli.

\section{LES ARMATURES DE PROJECTILES}

La petite base de l'armature trapézoïdale $\mathrm{n}^{\circ} 2156$ présente un enlèvement direct réfléchi. L'armature trapézoïdale $n^{\circ} 2574$ est affectée par deux enlèvements directs rasants et transversaux à la grande base (fig. 10). Ces enlèvements sont caractéristiques des armatures qui ont été tirées, comme en témoigne l'observation des pièces expérimentales. L'orientation de ces enlèvements indique un emmanchement en armatures tranchantes.

\section{DES GRATTOIRS POUR TRAVAILLER LA PEAU}

Deux lames et sept éclats ont travaillé la peau, correspondant à douze parties actives. Une lame (fig. 11, no 211) et sept éclats (fig. 11, n ${ }^{\text {os }} 213$ et 592) ont été retouchés en grattoirs et utilisés sur leurs parties distales. Une lame est fragmentée et a été utilisée sur la cassure distale. Le fragment de lame $\mathrm{n}^{\circ} 211$ a aussi été utilisé sur un angle de la cassure proximale. En plus de l'extrémité distale, le bord droit de l'éclat no 592 a travaillé la peau. Toutes les zones utilisées sont affectées par un émoussé important le long du fil actif, qui est quelquefois interrompu par des enlèvements directs sur la lame $\mathrm{n}^{\circ}$ 211. Dans tous les cas, le poli est à trame serrée et à réticulation très étroite (qui lui donne un aspect micropiqueté ou grenu; fig. 12). Le développement est plus important sur la face inférieure, mais l'extension transversale reste marginale. Quelques stries transversales étroites à fond lisse sont visibles. La distribution des traces et l'orientation des stries indiquent un mouvement transver-
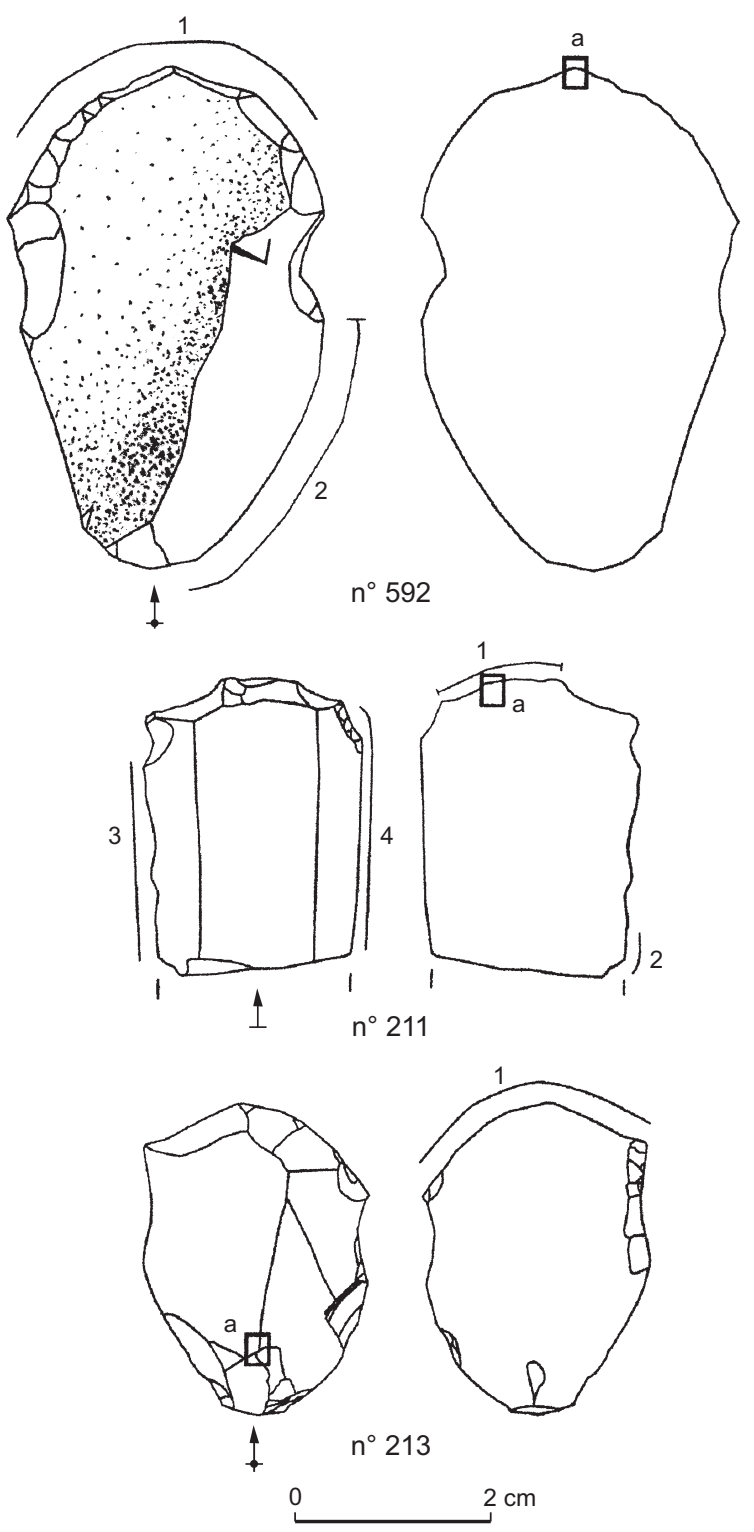

Fig. 11 - Le Pirou: grattoir sur lame $n^{\circ}$ 211, grattoir sur éclat $n^{\circ} 213$ et grattoir sur éclat cortical $n^{0} 592$ (silex bédoulien non chauffé) (dessin: L. Torchy).

sal en coupe négative, avec la face inférieure comme face d'attaque. Le poli observé a été remarqué sur les pièces expérimentales ayant travaillé la peau. La relative faible extension transversale des traces correspond à une matière plutôt rigide, il s'agit probablement d'un travail sur peau sèche. Sur la moitié proximale de l'éclat $n^{\circ} 213$, on observe des émoussements, polis et stries (perpendiculaires au front du grattoir) sur les parties saillantes des nervures (fig. 13). Les traces présentes sur ce grattoir sont interprétées comme 


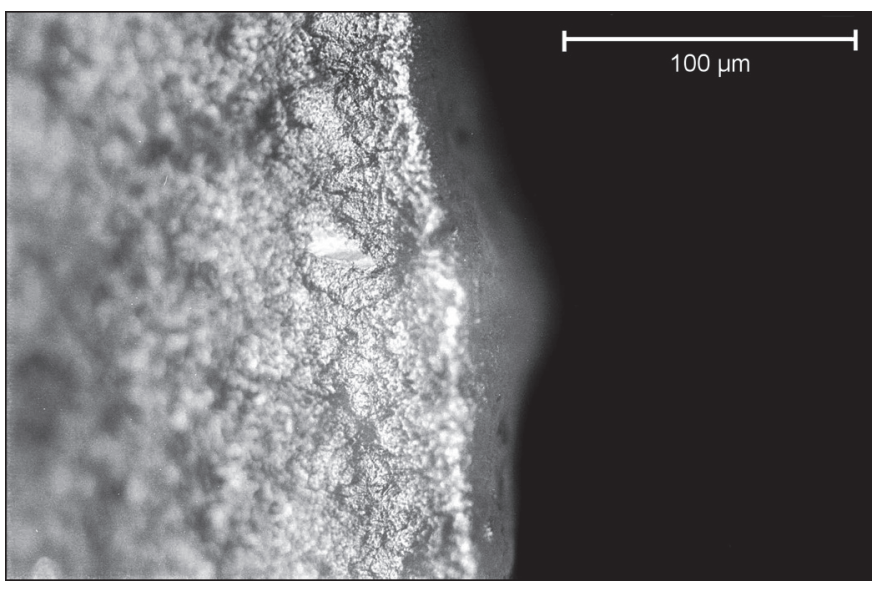

Fig. 12 - Le Pirou: poli marginal grenu sur éclat $n^{\circ} 592$ (photo prise en a fig. 11, 200x; cliché: L. Torchy).

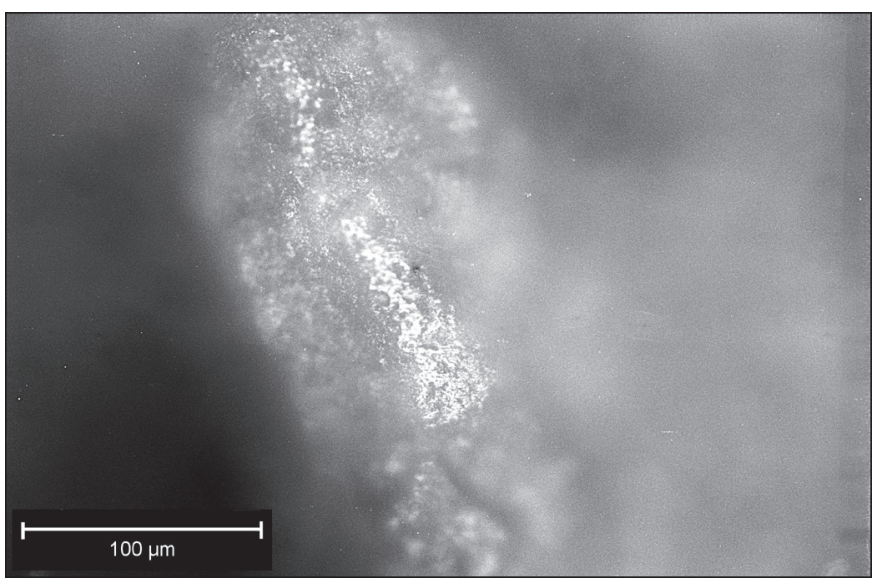

Fig. 13 - Le Pirou: traces d'emmanchement sur la face supérieure du grattoir $n^{0} 213$ (photo prise en a fig. 11, 200x; cliché: L. Torchy). étant liées à l'emmanchement (Rots, 2008). Un regroupement par classes morphométriques a été effectué pour l'ensemble des grattoirs du site. Cinq groupes ont été mis en évidence (fig. 14 et 15). Il est intéressant de noter que le grattoir présentant des traces d'emmanchement appartient à la classe $\mathrm{C}$, et que quatre grattoirs de cette classe (sur sept) ont été retrouvés dans la même fosse. Il paraît donc fort probable que ces grattoirs aient été retouchés pour être adaptés à un même système d'emmanchement, voire même à un seul manche comme cela a été observé pour les grattoirs éthiopiens (Ménard, 2008).

\section{DES LAMES POUR LE TRAVAIL DE L'OS}

Quatre outils ont été utilisés pour le travail de l'os, correspondant à six parties actives. Deux lames (fig. 16, $\mathrm{n}^{\text {os }} 182$ et 207) ont été utilisées sur les deux bords et deux autres sur un seul bord. Pour chaque zone d'utilisation, le bord est fortement affecté par des enlèvements visibles à l'œil nu, très nombreux ( $\mathrm{n}>15$ par $\mathrm{cm}$ ), alignés ou superposés, directs et inverses, de morphologie variable et à terminaison souvent en gradin. Les parties les plus proéminentes sont affectées par un poli d'extension marginale, de trame compacte avec des étirements du poli (fig. 17). La distribution des traces et les composantes linéaires présentes sur les zones polies indiquent un mouvement longitudinal. Les caractères du poli se retrouvent sur les pièces expérimentales ayant été utilisées pour tronçonner ou rainurer de l'os.
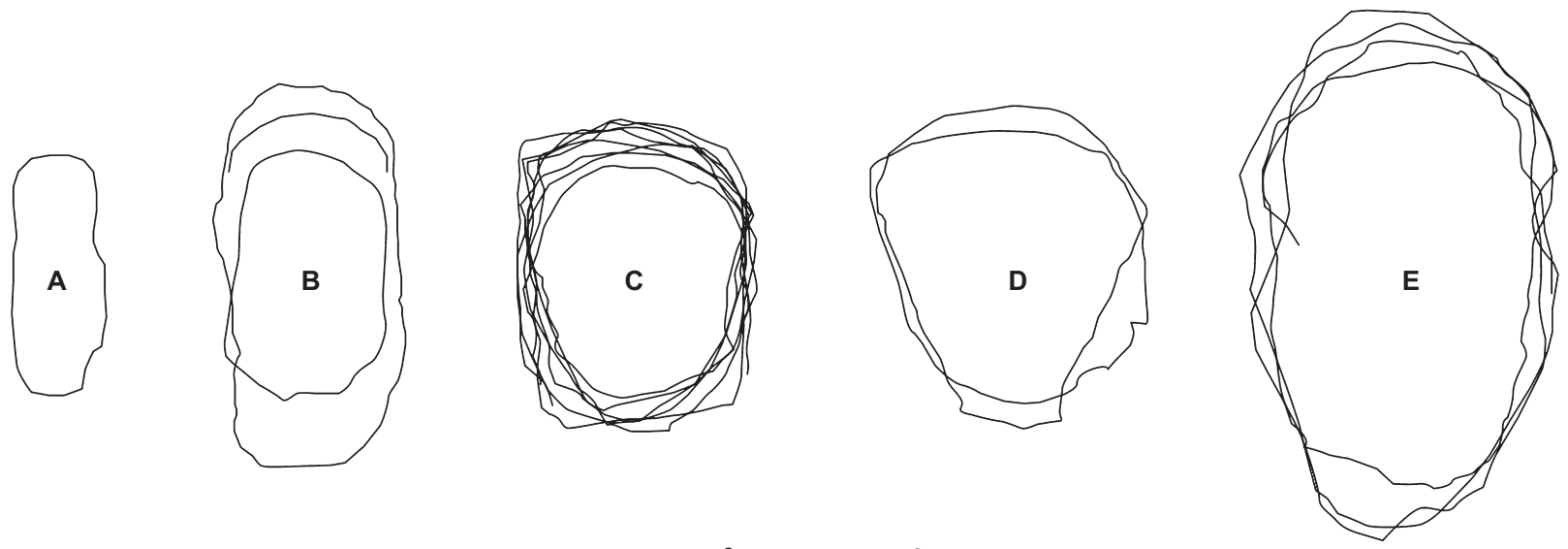

0 $2 \mathrm{~cm}$

Fig. 14 - Classes morphométriques des grattoirs du site du Pirou (DAO: L. Torchy). 


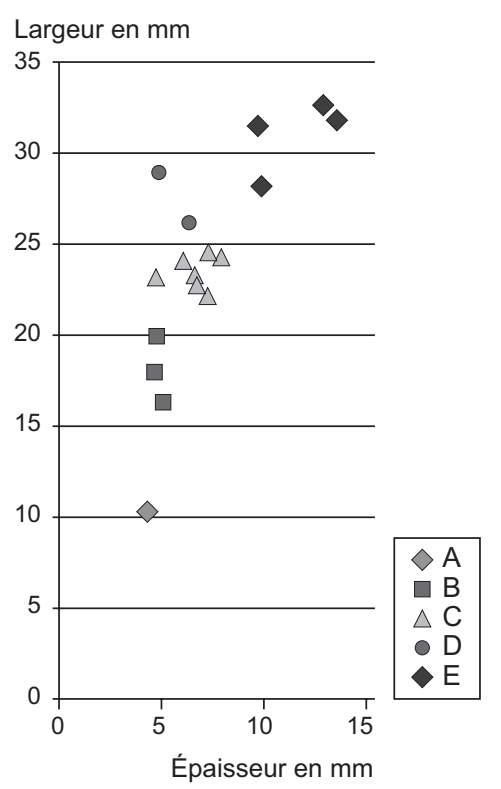

Fig. 15 - Le Pirou: nuage de points des grattoirs par classes morphométriques (DAO: L. Torchy).
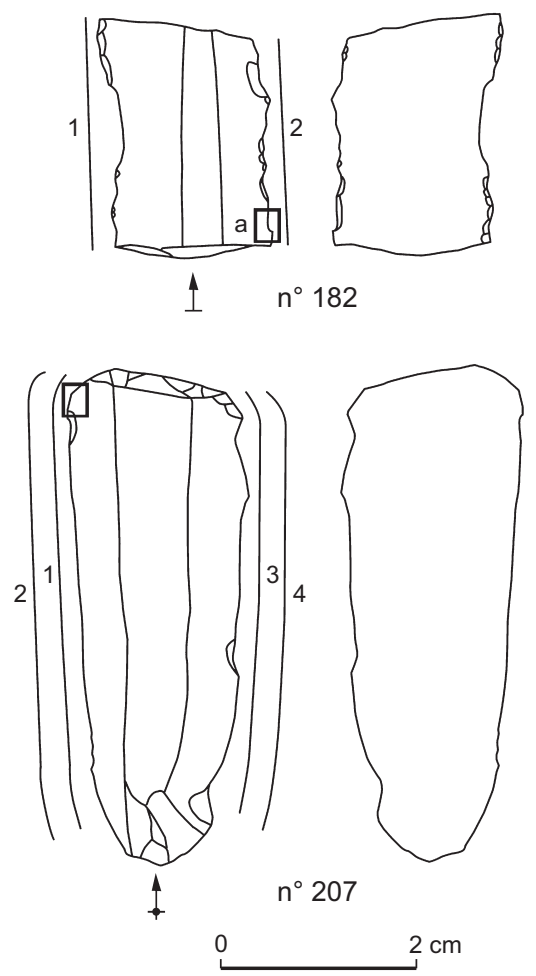

Fig. 16 - Le Pirou: fragment de lame $n^{0} 182$ et lame tronquée $n^{\circ} 207$ (silex bédoulien non chauffé) (dessin: L. Torchy).

\section{LE PERCAGE DE MATIÈRES MINÉRALES}

Trois supports (fig. 18, $\mathrm{n}^{\text {os }} 214$ et 1589) ont été retouchés sur leurs parties proximales afin de façonner des extrémités appointies. De forts émoussements et de larges stries transversales sont présents sur les nervures de ces extrémités (fig. 19). Les forts émoussements sont causés par une matière abrasive, et les stries larges ont été observées sur les pièces expérimentales ayant travaillé une matière minérale. Ces perçoirs auraient donc été utilisés pour percer des matières minérales sur une profondeur d'environ

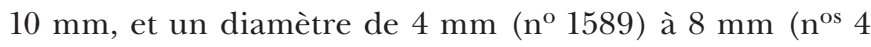
et 214). L'hypothèse de perçage de trous de réparation de céramique peut être formulée, sachant que cette activité a été observée sur l'industrie céramique du Pirou et que les diamètres des trous correspondent à la morphologie des perçoirs (Torchy, Gassin, 2010). Le perçage des éléments de parure présents sur le site est exclu, d'une part parce que les diamètres et profondeurs des trous sont plus petits et d'autre part, parce que rien n'indique qu'ils auraient été façonnés sur le site (communication orale de Hélène Vergély).

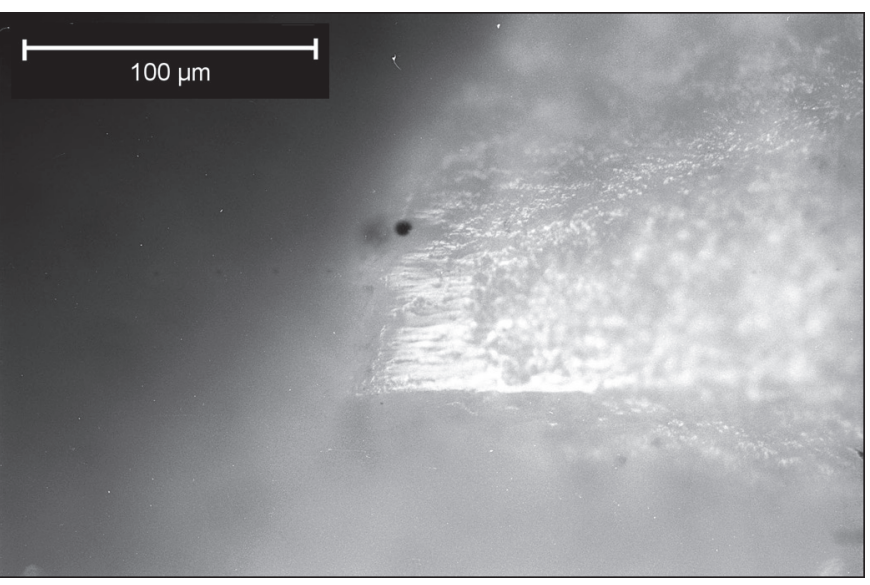

Fig. 17 - Le Pirou: poli compact avec poli étiré sur lame $n^{0} 182$ (photo prise en a fig. 16, 200x; cliché: L. Torchy). 


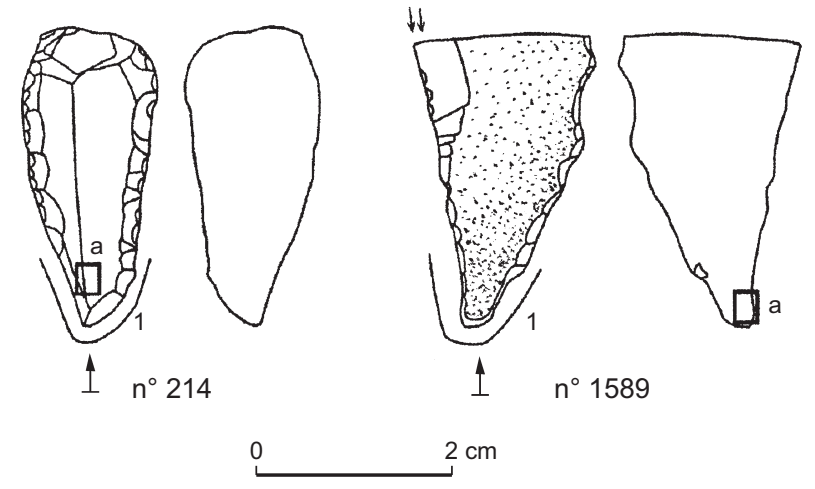

Fig. 18 - Le Pirou: perçoirs sur éclat $n^{0} 214$ et sur éclat cortical $n^{\circ} 1589$ (silex bédoulien non chauffé) (dessin: L. Torchy).

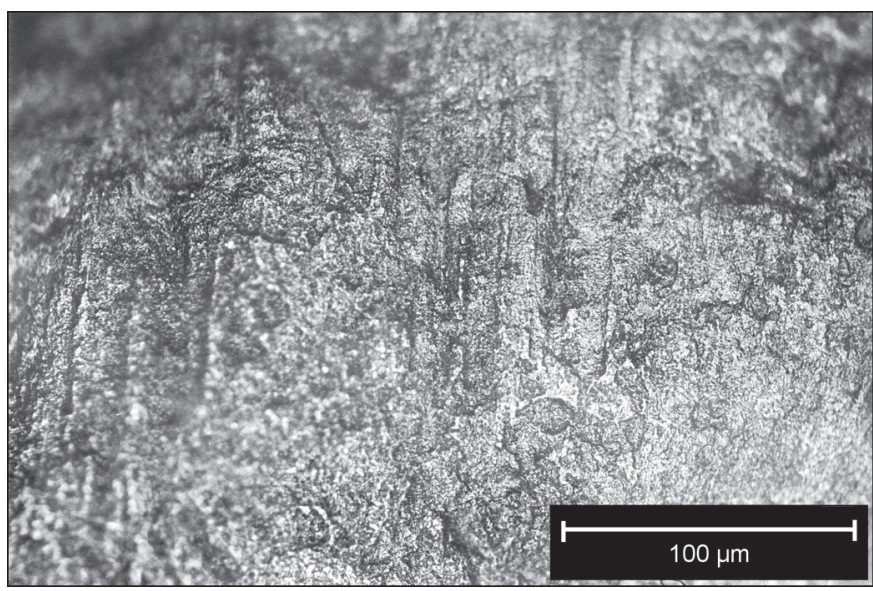

Fig. 19 - Le Pirou: stries larges transversales sur perçoir $n^{\circ} 1589$ (photo prise en a fig. 18, 200x; cliché: L. Torchy).

\section{L'INCISION D'UNE MATIÈRE MINÉRALE ?}

La lame $\mathrm{n}^{\circ} 8$ (fig. 20) est affectée par un fort émoussé grenu associé à un poli brillant bombé étiré et des stries obliques sur l'angle gauche de l'extrémité distale (fig. 21). L'émoussé indique le travail d'une matière abrasive, et le type de poli remarqué a été observé sur des pièces expérimentales ayant travaillé de l'argile sèche. L'extension des traces et l'orientation des stries correspondent à une incision d'une profondeur d'environ $4 \mathrm{~mm}$ grâce à l'angle de la lame. Cet outil pourrait bien être associé à la réalisation d'incisions techniques lors du montage d'un vase (fig. 22; Torchy, Gassin, 2010).

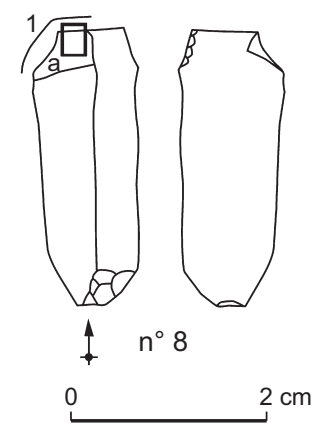

Fig. 20 - Le Pirou: fragment de lame $n^{0} 8$ (silex bédoulien non chauffé) (dessin: L. Torchy).

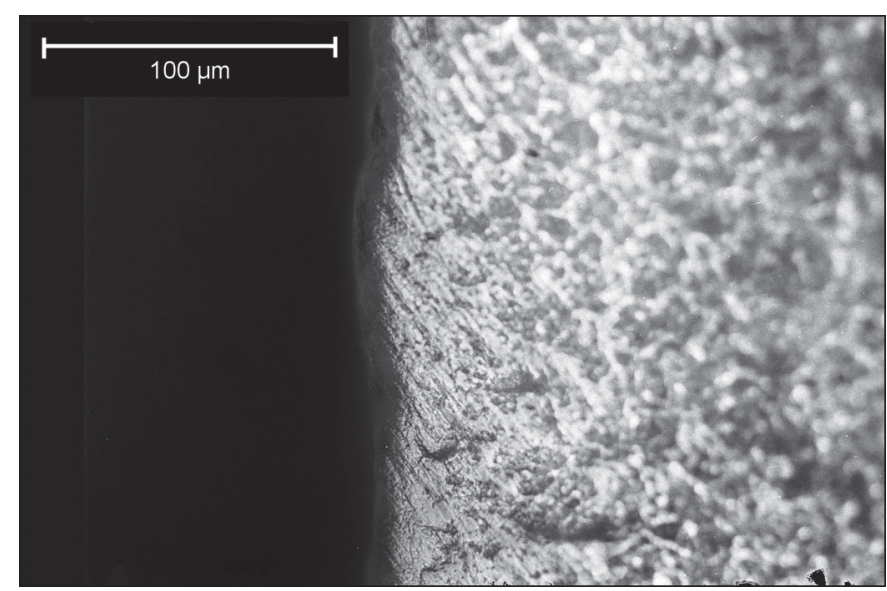

Fig. 21 - Le Pirou: stries obliques sur fort émoussé grenu et poli brillant bombé étiré sur lame $n^{\circ} 8$ (photo prise en a fig. 20, 200x; cliché: L. Torchy).

\section{DES PETITS ÉCLATS ET DES LAMELLES POUR DES UTILISATIONS BRÈVES SUR MATÉRIAUX TENDRES ?}

Des polis à trame ouverte ou semi-serrée sont visibles sur quatre lames et cinq éclats. Les traces décrites plus haut ont été observées sur des pièces expérimentales ayant été utilisées brièvement pour travailler des matières tendres (viande, peau fraîche), mais également sur trois lames ayant été transportées pendant quelques jours dans une poche de pantalon. Par conséquent, il n'est pas possible de proposer une interprétation à partir de la simple observation de polis peu développés sur une seule pièce. Néanmoins, une vision de l'ensemble des pièces permet de se rendre compte que ces zones polies se rencontrent en majorité à proximité des bords ou des extrémités distales, mais jamais sur les 

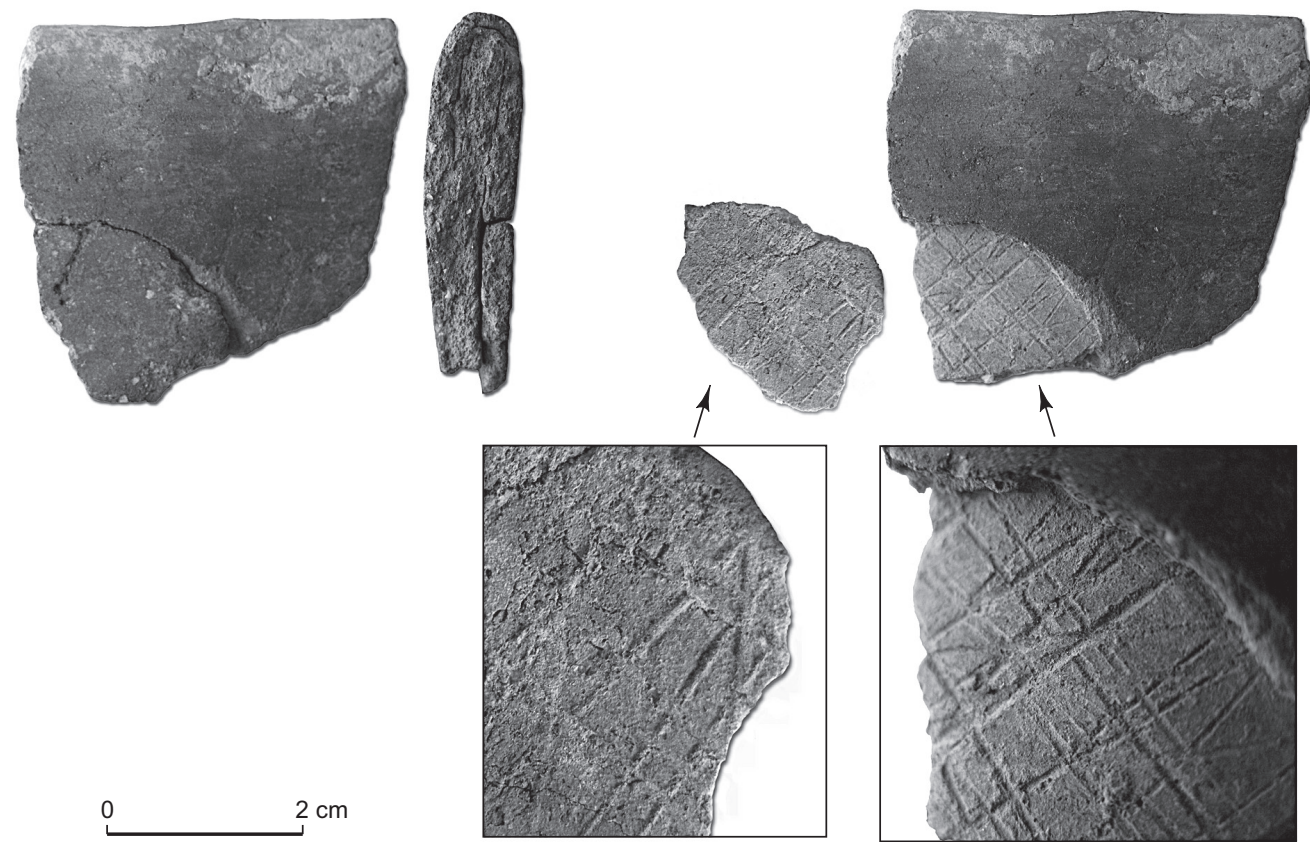

Fig. 22 - Le Pirou: incisions techniques sur tesson de céramique (cliché: M. Gandelin, Inrap).

nervures centrales et les talons. Ce constat permet d'affirmer qu'il s'agit bien de traces fonctionnelles, même si le fonctionnement et la matière travaillée ne sont pas connus.

\section{LANGEL À ARMISSAN}

\section{LA COUPE DE VÉGÉTAUX TENDRES}

Quatre lames (sept zones d'utilisation) ont été utilisées pour la coupe de végétaux tendres. Trois lames (fig. 23, $\mathrm{n}^{\text {os }} 39$ et 219) présentent des traces sur les deux bords et une lame (fig. 23, $\mathrm{n}^{\circ} 156$ ) a été utilisée uniquement sur le bord droit. Aucun poli n'est visible à l'œil nu. Au microscope, les polis visibles sur les lames $n^{\text {os }} 156$ et 219 sont de trame semiserrée, d'extension couvrante et parallèle au bord (fig. 24). Quelques stries longitudinales sont visibles. Les deux bords de la lame $\mathrm{n}^{\circ} 39$ sont affectés par un poli de texture grenue, parallèle au bord et d'extension couvrante. De nombreuses et larges stries longitudinales s'organisent le long du bord (fig. 25). Les traces observées sur les lames n ${ }^{\text {os }}$ 39, 156 et 219 ont été remarquées sur les pièces expérimentales ayant servi à couper des végétaux tendres pendant une courte durée, comme cela a déjà été expliqué plus haut pour certaines lames du site du Pirou. La lame $n^{\circ} 39$ présente des traces différentes. Les stries et l'extension couvrante du poli indi- quent respectivement un fonctionnement longitudinal et une matière travaillée très tendre, probablement végétale. Plusieurs hypothèses peuvent être formulées pour expliquer le fait que le poli soit grenu et que les stries soient larges. La texture du poli pourrait être causée par une composante minérale, comme cela a été vu sur les expérimentations de J. F. Gibaja Bao (2003). L'aspect du poli et des stries pourrait résulter d'un phénomène taphonomique. En effet, les expérimentations de $\mathrm{H}$. Plisson sur l'altération des polis ont montré qu'un poli végétal lisse pouvait être modifié en poli grenu après avoir passé plusieurs mois en milieu alcalin, et que les stries pouvaient se retrouver élargies (Plisson, 1985 et 1986; Plisson, Mauger, 1988). Il est difficile de trancher entre ces deux hypothèses, mais le fait que la totalité du poli soit micropiqueté plaide en faveur de la seconde.

\section{LE RACLAGE DE VÉGÉTAUX}

Une lame transformée en burin a été utilisée pour le raclage de végétaux (fig. 26). Un poli à trame compacte et d'extension marginale est présent sur le pan du burin sur lame $n^{\circ} 64$ (fig. 27). Sur la face inférieure, la trame du poli est semi-serrée, toujours d'extension marginale, et quelques stries transversales sont visibles. Les quelques stries indiquent un fonctionnement en mouvement transversal. 

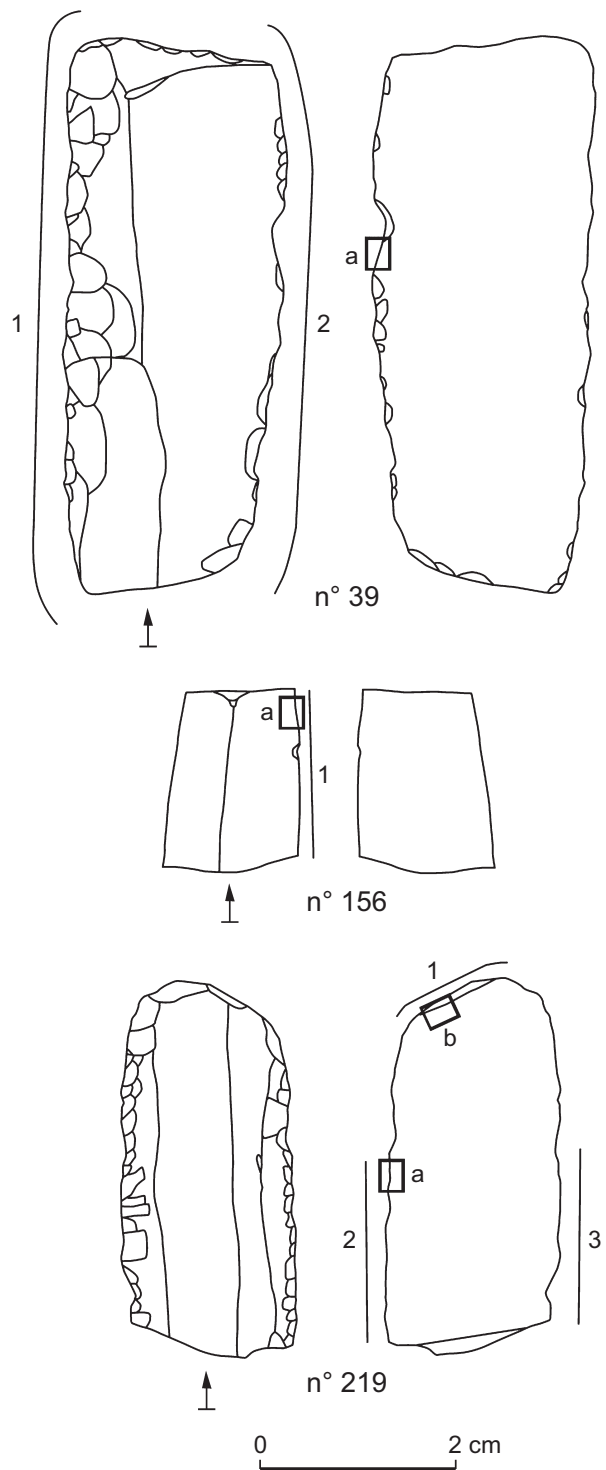

Fig. 23 - Langel: fragments de lames $n^{o s}$ 39, 156 et 219 (silex bédoulien non chauffé) (dessin: L. Torchy).

L'association d'un poli compact sur le pan du burin et d'un poli semi-serré sur la face inférieure suggère un fonctionnement en coupe négative avec le pan du burin comme face d'attaque. Ces polis sont cependant trop peu développés pour pouvoir faire une distinction entre un travail du bois et celui d'une matière végétale tendre rigide.

\section{LES ARMATURES DE PROJECTILES}

Des enlèvements burinants, tous deux sur les bords gauches, sont visibles sur les extrémités distales des arma-

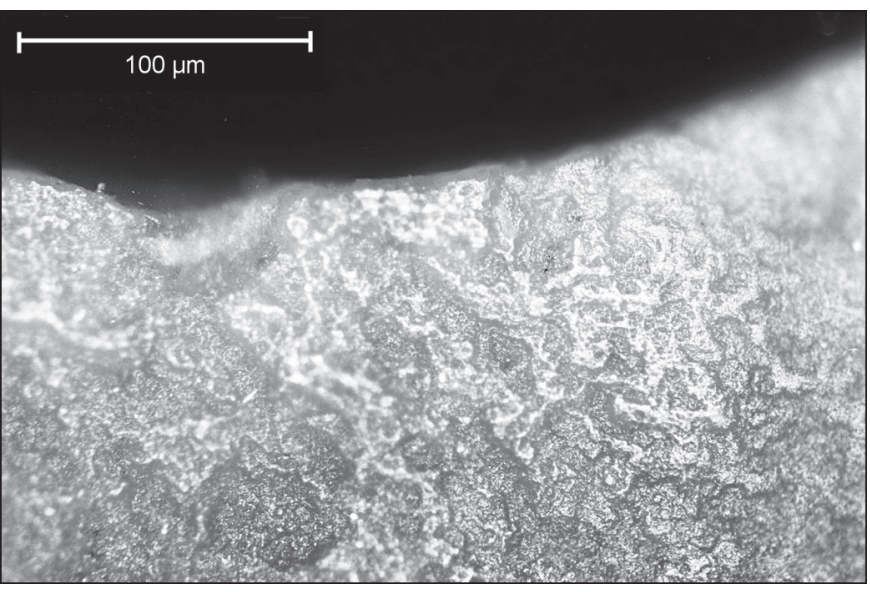

Fig. 24 - Langel: poli à trame semi-serrée sur lame $n^{0} 219$ (photo prise en a fig. 23, 200x; cliché: L. Torchy).

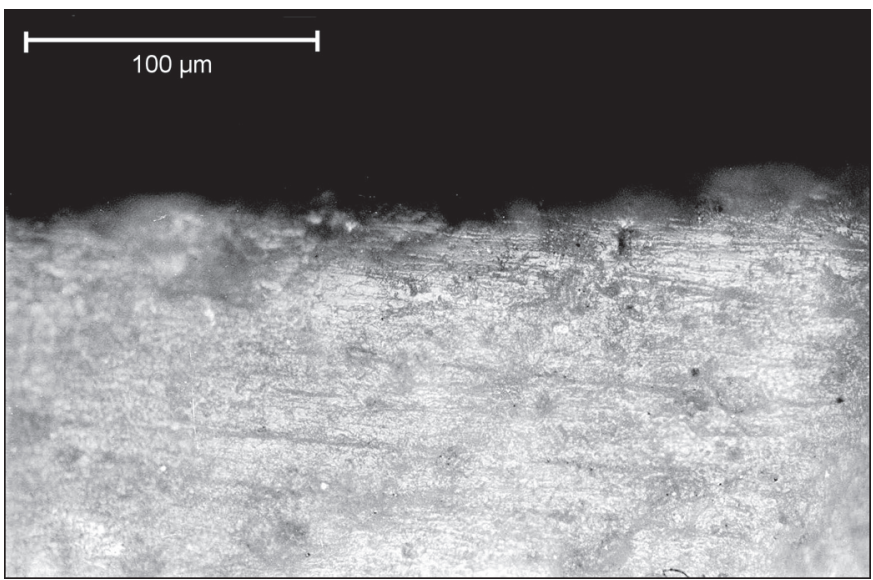

Fig. 25 - Langel: poli grenu et stries longitudinales sur lame $n^{\circ} 39$ (photo prise en a fig. 23, 200x; cliché: L. Torchy).

tures trapézoïdales $\mathrm{n}^{\text {os }} 3$ et 7 . Deux enlèvements inverses rasants affectent le bord droit de la pièce $n^{\circ} 7$. Une fracture en charnière est observée sur le bord droit de la pièce $n^{\circ} 13$ (fig. 28). Les pièces $n^{\text {os }} 3$ et 7 ont été utilisées en armatures de flèches tranchantes, comme l'indique l'orientation des traces d'impacts. L'armature $\mathrm{n}^{\circ} 13$ a également été tirée, mais sa morphologie initiale n'est pas connue et il n'est pas possible d'affirmer si à l'origine elle était de type tranchant ou perçant.

\section{LE TRAVAIL DE LA PEAU}

Trois lames et un éclat ont été utilisés pour le travail de la peau, soit quatre parties actives. Une lame (fig. 29, 


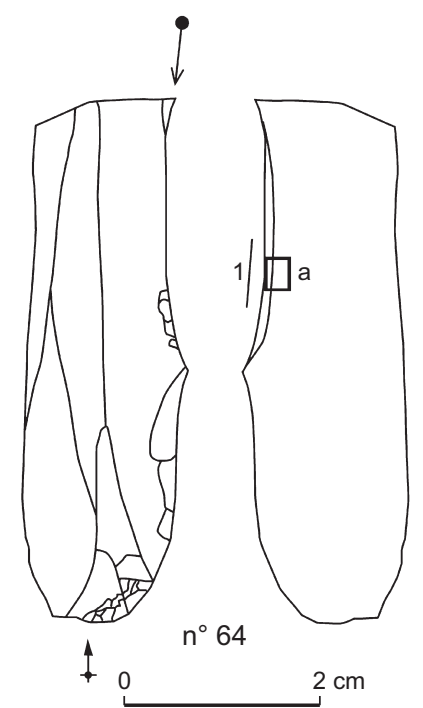

Fig. 26 - Langel: burin sur lame $n^{0} 64$ (silex bédoulien non chauffé) (dessin: L. Torchy).

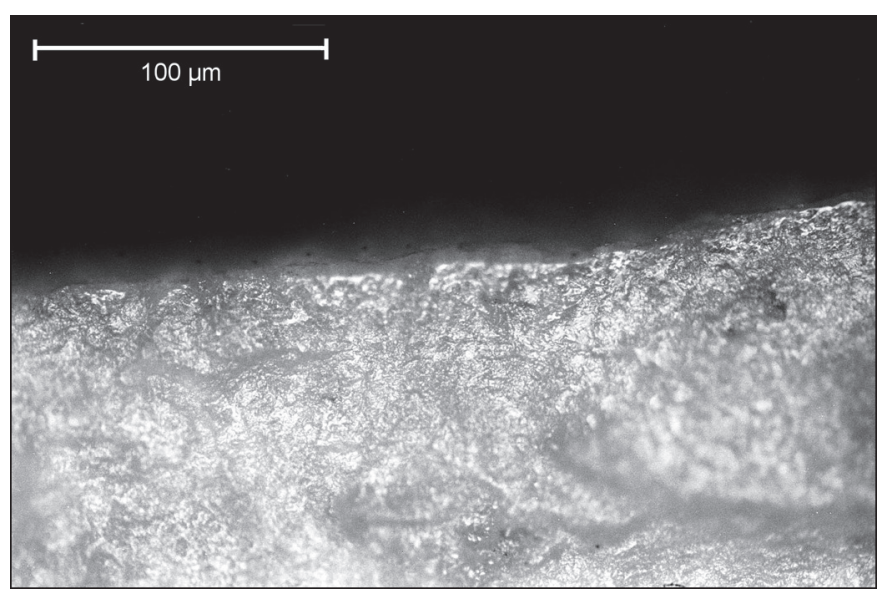

Fig. 27 - Langel: poli végétal peu développé sur le pan du burin $n^{0} 64$ (photo prise en a fig. 26, 200x; cliché: L. Torchy).

$n^{\circ}$ 26) et un éclat ont été retouchés en grattoirs et utilisés sur leurs extrémités distales. Deux lames sont fragmentées et respectivement utilisées sur leurs parties proximale et distale (fig. 29, $\mathrm{n}^{\circ}$ 165). Les quatre outils ont en commun un émoussé important et continu le long du fil actif et sont affectés par un poli à trame serrée et à réticulation très étroite (qui lui donne un aspect micropiqueté ou grenu, fig. 30), dont le développement est plus important sur la face inférieure. Quelques stries transversales étroites à fond lisse sont visibles sur les quatre pièces. L'extension transver-
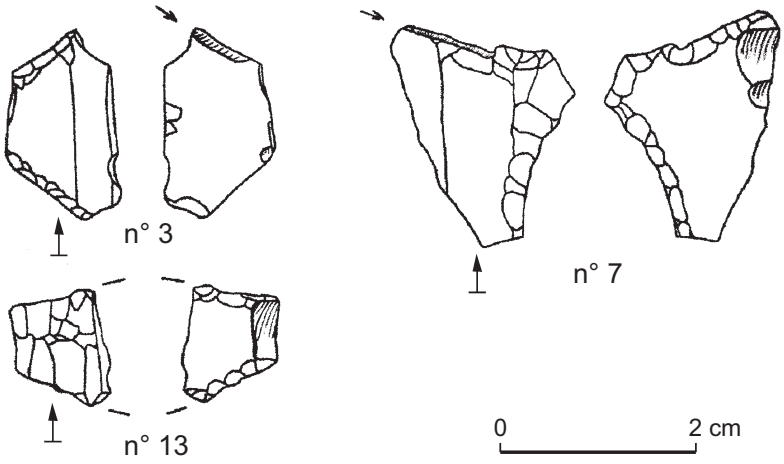

Fig. 28 - Langel: armatures trapézoïdales sur lame $n^{0} 3$ et sur éclat $n^{\circ} 7$, fragment d'armature $n^{0} 13$ (silex bédoulien non chauffé). Les enlèvements ombragés sont dus aux impacts (dessin: L. Torchy).
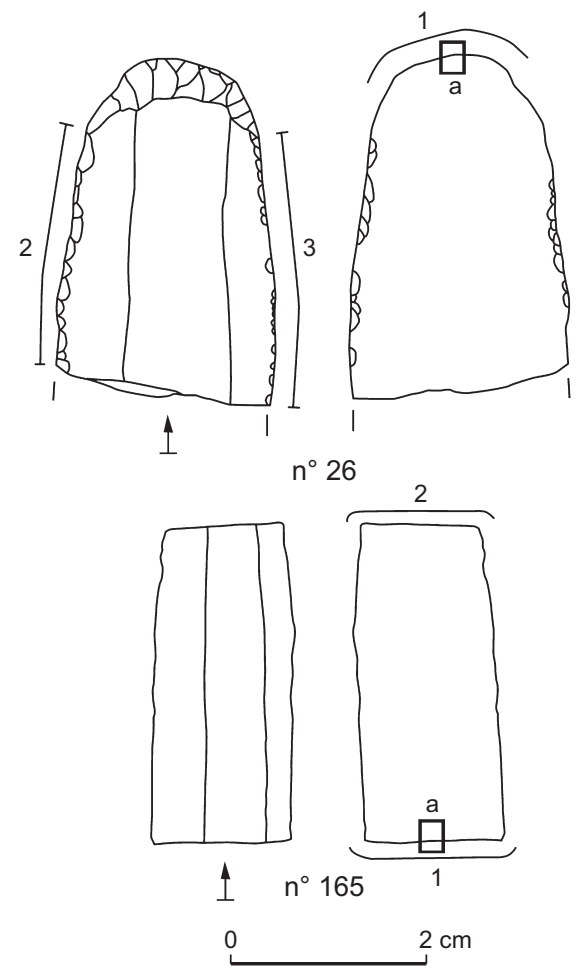

Fig. 29 - Langel: grattoir sur lame $n^{0} 26$ et fragment de lame $n^{0} 165$ (silex bédoulien non chauffé) (dessin: L. Torchy).

sale des traces sur la face inférieure est toujours marginale, mais varie entre 10 et 50 microns. Les traces observées ont leur équivalent dans le référentiel expérimental et correspondent au travail de la peau. Les stries indiquent un mouvement transversal, et la faible extension du poli suggère une faible pénétration dans la matière, qui devait être plutôt rigide: il s'agirait donc probablement de peau sèche. 


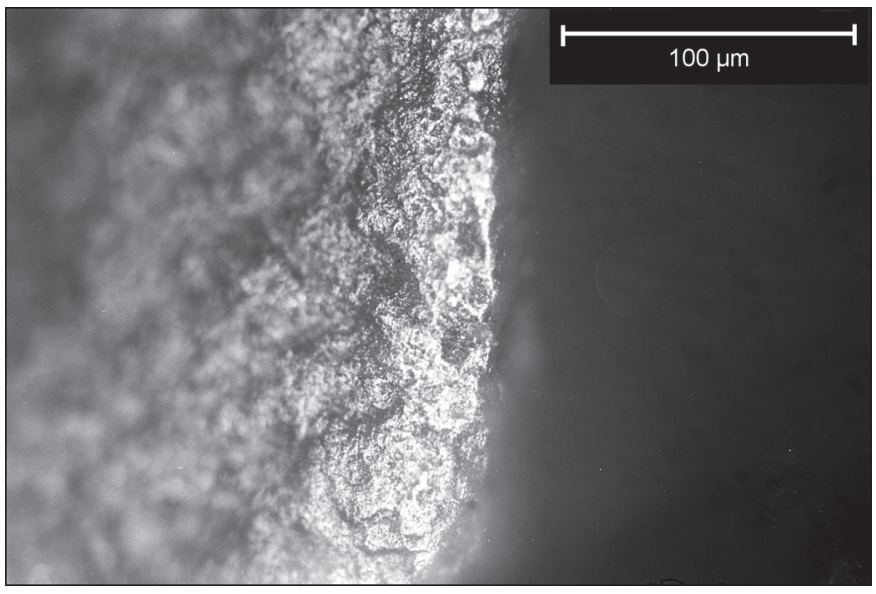

Fig. 30 - Langel: poli grenu sur lame $n^{0} 219$ (photo prise en b fig. 23, 200x; cliché: L. Torchy).

\section{LE TRAVAIL DES MATIÈRES INDÉTERMINÉES}

Un outil a travaillé une matière indéterminée sur une zone active. Un grattoir sur éclat présente sur la face inférieure un poli à trame ouverte, d'extension marginale, et quelques stries transversales. Les stries transversales indiquent un fonctionnement transversal, mais la matière travaillée ne peut être déterminée en raison du faible développement des traces.

\section{AURIAG À CARCASSONNE}

\section{DES LAMELLES POUR RACLER DES VÉGÉTAUX}

Trois lamelles, dont deux transformées en burin, ont été utilisées sur cinq parties actives. Deux zones d'utilisation sont visibles sur le flanc droit du burin sur lamelle chauffée no 390 (fig. 31). Sur le pan du burin, les deux zones (l'une vers la face supérieure et l'autre vers la face inférieure) montrent un poli à trame compacte, à microtopographie moutonnante et d'extension marginale (fig. 32). Sur les faces inférieure et supérieure se trouve un poli à trame compacte avec de nombreuses stries transversales, légèrement obliques (fig. 33). Il s'agit d'un raclage en coupe négative de végétaux rigides tendres. Ce mode d'utilisation des burins est fréquent dans les assemblages lithiques du Chasséen méridional. Toutefois, le bord latéral des burins est systématiquement utilisé avec la face inférieure en dépouille et le pan comme face d'attaque. L'utilisation de la face supérieure comme face en dépouille, déjà remarquée pour un burin du secteur PIV, demeure exceptionnelle (Gassin, Astruc et al., 2006).

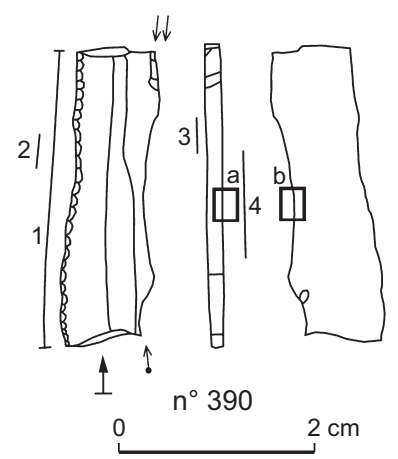

Fig. 31 - Auriac St2: burin sur fragment de lamelle à retouches latérales directes $n^{\circ} 390$ (silex bédoulien chauffé) (dessin: L. Torchy).

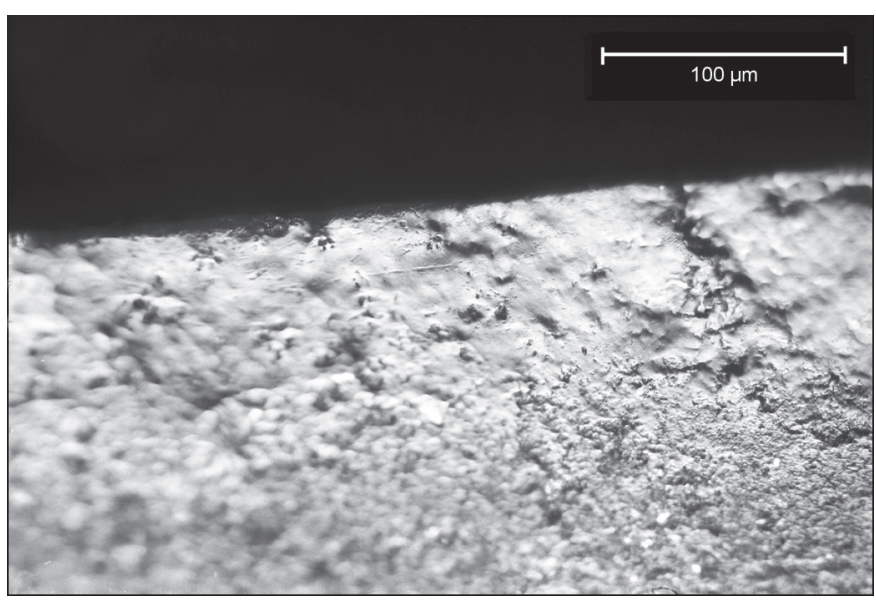

Fig. 32 - Auriac St2: poli compact couvrant sur lamelle $n^{\circ} 390$ (photo prise en a fig. 31, 200x; cliché: L. Torchy).

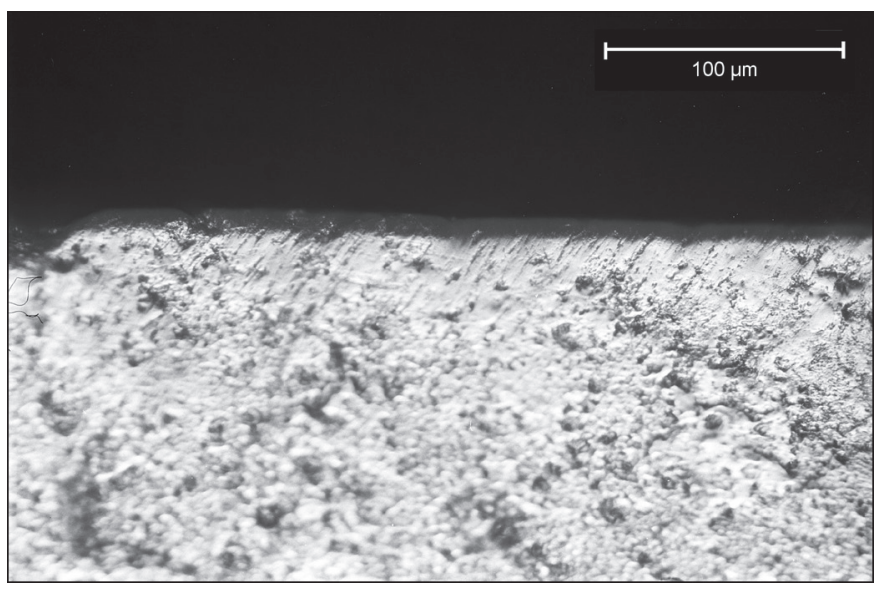

Fig. 33 - Auriac St2: poli compact et stries transversales obliques sur lamelle $n^{0} 390$ (photo prise en b fig. 31, 200x; cliché: L. Torchy). 


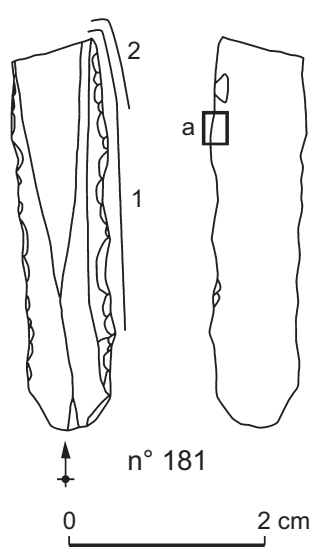

Fig. 34 - Auriac St2: fragment de lamelle à retouches latérales directes (silex bédoulien non chauffé) (dessin: L. Torchy).

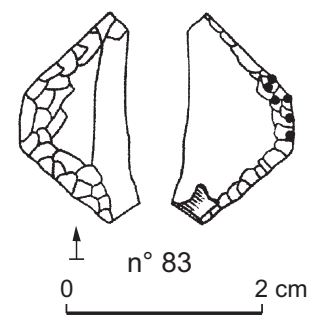

Fig. 35 - Auriac St2: armature trapézoïdale $n^{0} 83$ (silex bédoulien chauffé). L'enlèvement ombragé est dû à l'impact et les points noirs matérialisent les concentrations de résidus d'adhésif (dessin: L. Torchy).

\section{DES LAMELLES POUR COUPER DES VÉGÉTAUX}

Deux outils ont coupé des végétaux, soit deux parties actives. Les bords droits d'une lamelle non chauffée (fig. 34, no 181) et d'une lamelle chauffée sont affectés par un poli brillant visible à l'œil nu. À fort grossissement, la trame de ce poli est serrée, de microtopographie bombée et d'extension couvrante. On observe des stries longitudinales et étroites. Les stries indiquent un fonctionnement longitudinal, et les caractères du poli correspondent aux pièces expérimentales qui ont coupé des végétaux tendres.

\section{LES ARMATURES DE PROJECTILES}

L'armature trapézoïdale no 83 est affectée par un enlèvement inverse rasant, en partie proximale, qui indique qu'elle a été tirée (fig. 35). Des résidus noirs visibles à l'œil nu sont concentrés vers la partie distale de la petite base (fig. 36). Dans notre référentiel expérimental, ce cas a été

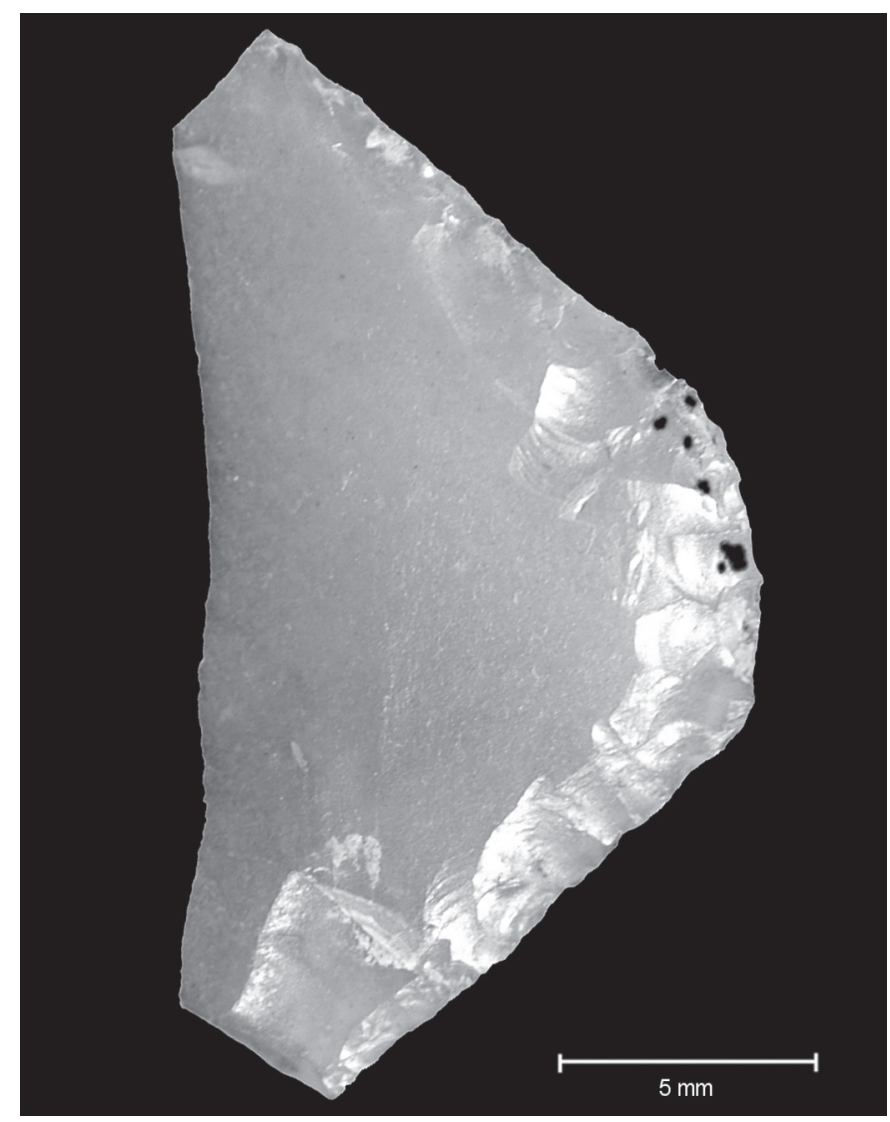

Fig. 36 - Auriac St2: armature trapézoïdale $n^{\circ} 83$ (silex bédoulien chauffé) (cliché: L. Torchy).

observé aussi bien sur les armatures perçantes que sur les armatures tranchantes. Par conséquent, il n'est pas possible d'en déduire le sens d'emmanchement.

\section{DES GRATTOIRS POUR TRAVAILLER LA PEAU}

Trois lamelles et un éclat en silex bédoulien chauffé ont été utilisés pour le travail de la peau sèche. Deux lamelles (fig. 37, no 397) ont été retouchées en grattoirs et utilisées sur leurs extrémités distales. Le bord gauche d'une autre lamelle est affecté par des retouches directes semi-abruptes, et présente des traces d'utilisation. Un éclat (fig. 37, no 431) a été retouché en grattoir et utilisé. Chacune de ces zones utilisées présente un émoussé important le long du fil actif. Dans tous les cas, le poli est à trame serrée et à réticulation très étroite (qui lui donne un aspect micropiqueté ou grenu, fig. 38). Quelques stries transversales étroites à fond lisse sont visibles sur toutes les pièces, avec en plus des stries longitudinales sur l'une d'entre elles. Comme cela 
a été expliqué pour les deux sites précédemment étudiés, ces traces correspondent à un travail de raclage de la peau sèche en coupe négative. Pour le cas de la lamelle no 390 (fig. 31), le fonctionnement est plus complexe, les stries longitudinales indiquent aussi un mouvement longitudinal, qui correspond probablement à la découpe de la peau.
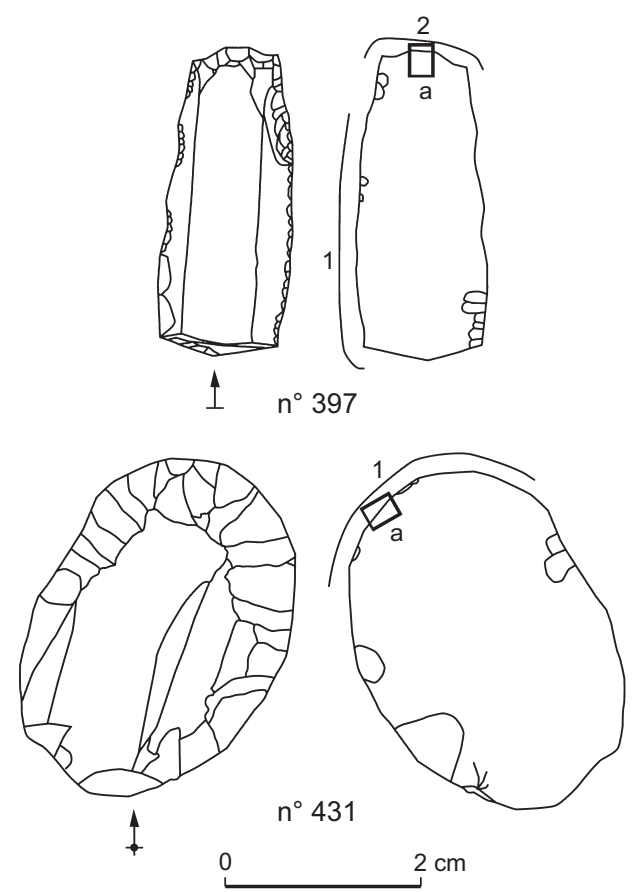

Fig. 37 - Auriac St2: grattoir sur lamelle $n^{0} 397$ et grattoir sur éclat $n^{0} 431$ (silex bédoulien chauffé) (dessin: L. Torchy).

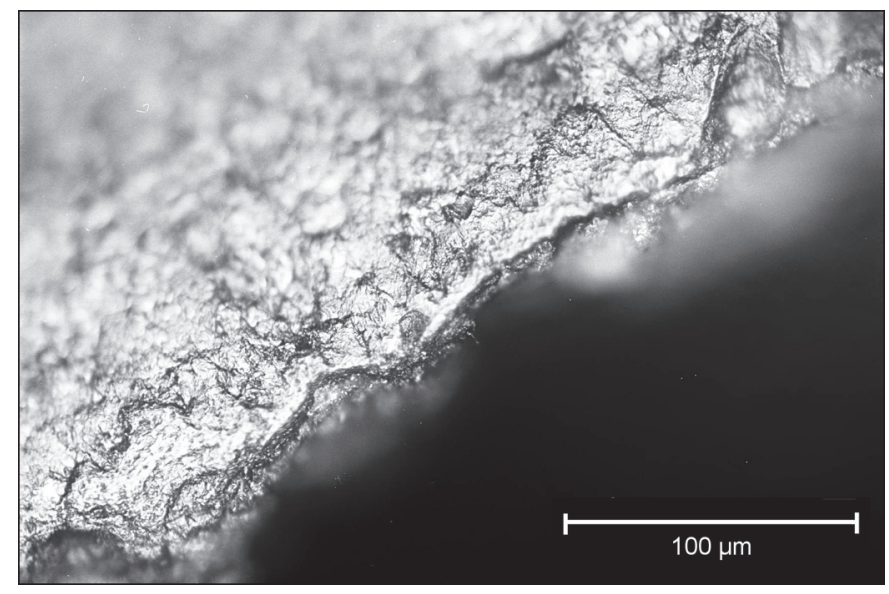

Fig. 38 - Auriac St2: poli compact micropiqueté sur éclat $n^{0} 431$ (photo prise en a fig. 37, 200x; cliché: L. Torchy).

\section{LE TRAVAIL DE L'OS}

Une pièce a été utilisée pour travailler l'os sur une zone active. Des points de poli à trame compacte et extension marginale sont présents sur les proéminences de la partie distale du bord gauche de la lame $n^{\circ} 495$ (fig. 39). Des composantes linéaires avec effet d'étirement du poli sont visibles sur la plupart de ces zones (fig. 40). Les traces observées sur la lame $n^{\circ} 495$ correspondent à un fonctionnement longitudinal sur une matière dure. Les étirements de poli se retrouvent sur les pièces expérimentales ayant servi à travailler de l'os. Il pourrait s'agir soit d'une phase de sciage dans la chaîne opératoire de la boucherie, soit d'un rainurage d'os pour conduire le débitage. L'étude de l'outillage osseux du site d'Auriac a montré que la technique la plus fréquemment utilisée pour le débitage d'os

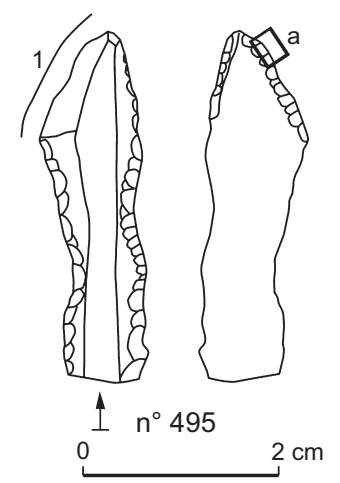

Fig. 39 - Auriac St2: lamelle à retouches latérales directes et retouches distales inverses (silex bédoulien chauffé) (dessin: L. Torchy).

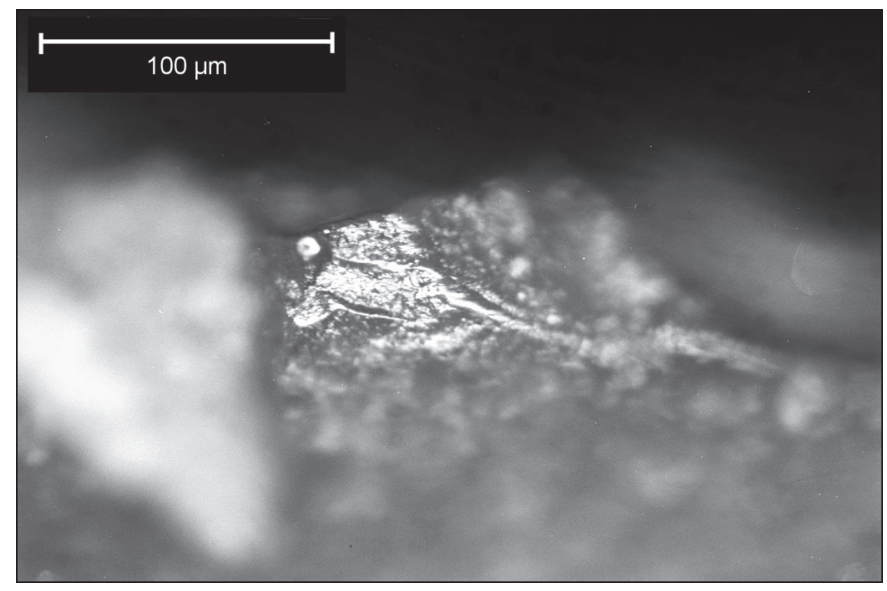

Fig. 40 - Auriac St2: poli compact marginal de la lame $n^{\circ} 495$ (photo prise en a fig. 39, 200x; cliché: L. Torchy). 
était le sciage longitudinal, et signale de plus du rainurage et du tronçonnage (Gaillard, 1998). La lame $n^{\circ} 495$ a pu être utilisée pour n'importe laquelle de ces activités.

\section{UN ÉGLAT NON CHAUFFÉ POUR TRAVAILLER UNE MATIÈRE MINÉRALE}

L'éclat non chauffé $\mathrm{n}^{\circ} 406$ (fig. 41) présente de forts émoussement visibles à l'œil nu sur l'extrémité distale ainsi que sur les deux bords (fig. 42). De larges stries transversales sont visibles à la loupe binoculaire. Les forts émoussements associés à de larges stries transversales indiquent un travail de raclage de matières minérales plutôt tendres, et probablement pendant une durée relativement longue.

\section{DES UTILISATIONS BRÈVES ?}

Des enlèvements alignés, soit directs, soit inverses, sont présents sur quatre éclats et huit lamelles. Ces enlèvements sont trop petits pour être de la retouche volontaire, et la distribution exclut qu'ils puissent être d'ordre taphonomique. Il paraît donc probable que ces lames aient été utilisées en mouvement transversal, mais les polis sont trop peu marqués pour pouvoir interpréter la matière travaillée, il s'agit probablement d'une courte durée d'utilisation.

\section{GESTION DES PRODUCTIONS LITHIQUES}

Avant d'aborder la question des différences de gestion des productions lithiques, il faut rappeler qu'il existe une disparité d'ordre chronologique entre les sites du Pirou et de Langel d'une part, et celui d'Auriac d'autre part. De ce fait, la représentation des matières premières dans les assemblages est fondamentalement différente. Sur les deux sites chasséens anciens, le silex bédoulien chauffé est représenté par un ou deux éléments, alors que sur le site d'Auriac, il représente plus de $90 \%$. Certaines productions ne seront donc pas directement comparables.

Sur le site d'Auriac, on observe pratiquement la même intensité d'utilisation sur les productions en silex chauffé que sur les productions en silex non chauffé (tabl. II). Cela semble logique étant donné la similitude de modules entre les éléments chauffés et non chauffés (entre 8 et $12 \mathrm{~mm}$ de largeur). Mais l'on peut se demander, comme pour le site de Lattes (Léa, 2004b), pourquoi des lamelles en silex bédoulien non chauffé ont été importées alors que le silex bédoulien chauffé est présent en grande quantité. De plus, il faut signaler que sur le site d'Auriac, on ne retrouve que

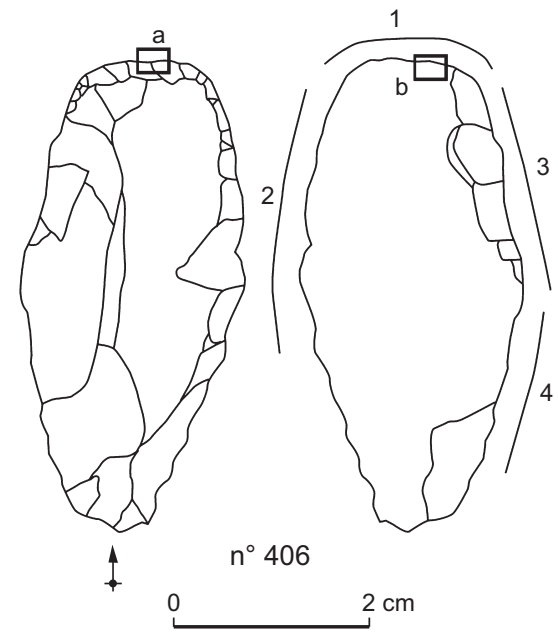

Fig. 41 - Auriac St2 : éclat retouché $n^{0} 406$ (silex bédoulien non chauffé) (dessin: L. Torchy).

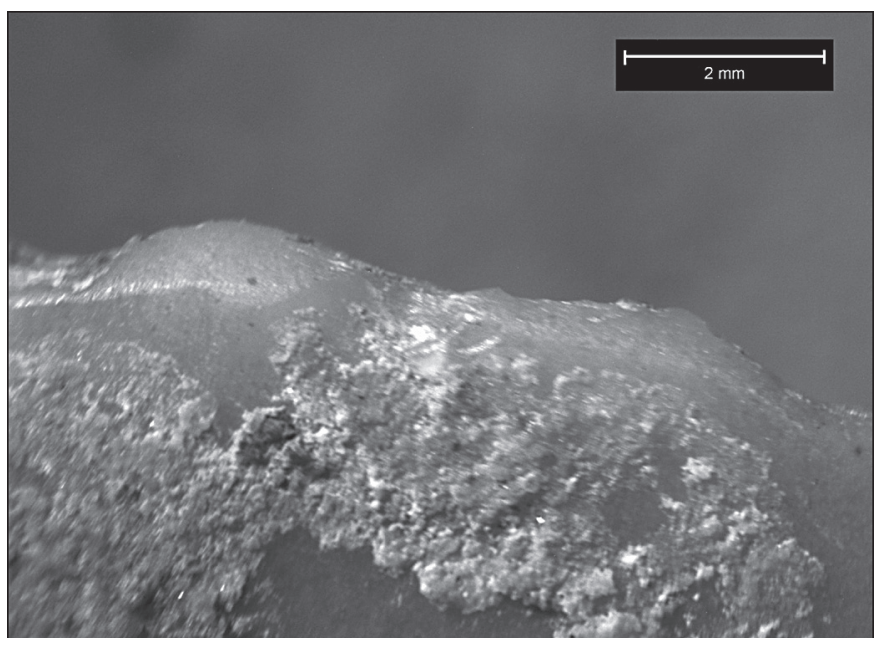

Fig. 42 - Auriac St2: fort émoussé sur éclat $n^{\circ} 406$ (photo prise en b fig. 41, 10x; cliché: L. Torchy).

très peu de grandes lames débitées par percussion indirecte sur silex bédoulien non chauffé (Vaquer, Remicourt, 2010) qui sont pourtant fréquentes dans les assemblages du Chasséen méridional (Léa, ibidem).

Au sein des productions en silex bédoulien non chauffé, surtout analysable sur les sites du Pirou et de Langel, on observe une plus grande intensité d'utilisation sur les lames que sur les éclats. Les lames de largeur supérieure à 12 mm ont été utilisées pour couper des végétaux tendres pour la majorité d'entre elles, mais aussi pour travailler de l'os, et pour racler de la peau sèche lorsqu'elles sont retouchées en 
Tabl. II - Intensité d’utilisation pour les différentes productions des trois sites étudiés.

\begin{tabular}{|c|c|c|c|c|c|c|c|}
\hline Site & MP & Produit & $\begin{array}{c}\text { Total } \\
\text { échantillon }\end{array}$ & $\begin{array}{c}\text { Effectif } \\
\text { pièces utilisées }\end{array}$ & Nb ZU & $\begin{array}{c}\text { Nb ZU moyen } \\
\text { par pièce utilisée }\end{array}$ & $\begin{array}{c}\mathrm{Nb} \mathrm{ZU} \\
\text { moyen total }\end{array}$ \\
\hline \multirow{3}{*}{ Le Pirou } & \multirow{2}{*}{ silex bédoulien non chauffé } & lames & 32 & 23 & 45 & 1,95 & 1,4 \\
\hline & & éclats & 65 & 22 & 27 & 1,22 & 0,41 \\
\hline & silex bédoulien chauffé & lamelles & 1 & 0 & 0 & - & - \\
\hline \multirow{3}{*}{ Langel } & \multirow{2}{*}{ silex bédoulien non chauffé } & lames & 16 & 7 & 13 & 1,85 & 0,81 \\
\hline & & éclats & 18 & 4 & 4 & 1 & 0,22 \\
\hline & silex bédoulien chauffé & lamelles & 2 & 0 & 0 & - & - \\
\hline \multirow{4}{*}{ Auriac St2 } & \multirow{2}{*}{ silex bédoulien non chauffé } & lamelles & 6 & 3 & 5 & 1,66 & 0,83 \\
\hline & & éclats & 3 & 1 & 3 & 3 & 1 \\
\hline & \multirow{2}{*}{ silex bédoulien chauffé } & lamelles & 37 & 17 & 27 & 1,59 & 0,73 \\
\hline & & éclats & 10 & 4 & 4 & 1 & 0,4 \\
\hline
\end{tabular}

Tabl. III - Auriac St2, intensité d'utilisation des lamelles en silex bédoulien chauffé en fonction du code opératoire.

\begin{tabular}{|c|c|c|c|c|c|}
\hline $\begin{array}{c}\text { Code } \\
\text { opératoire }\end{array}$ & $\begin{array}{c}\text { Total } \\
\text { échantillon }\end{array}$ & $\begin{array}{c}\text { Effectif } \\
\text { pièces utilisées }\end{array}$ & Nb ZU & $\begin{array}{c}\text { Nb ZU moyen } \\
\text { par pièce utilisée }\end{array}$ & $\begin{array}{c}\text { Nb ZU } \\
\text { moyen total }\end{array}$ \\
\hline $12 / 21$ & 4 & 1 & 1 & 1 & 0,25 \\
\hline $123 / 321$ & 7 & 2 & 4 & 2 & 0,57 \\
\hline 212 & 21 & 10 & 15 & 1,5 & 0,71 \\
\hline+ de 3 & 5 & 4 & 7 & 1,75 & 1,4 \\
\hline
\end{tabular}

grattoir. Les lames de largeur inférieure à $12 \mathrm{~mm}$ présentent rarement des traces. Si elles ont été utilisées, c'est soit brièvement, soit pour un travail sur matière très tendre. Pour les éclats, on observe une césure aux alentours de $15 \mathrm{~mm}$ de largeur. Les modules les plus importants ont été souvent retouchés en grattoirs et utilisés pour le raclage de la peau, mais aussi pour la coupe de végétaux par les bords restés bruts sur le site du Pirou (parfois sur le même éclat). Les éclats les plus petits ont parfois été façonnés en armatures de flèche et tirés. Pour les éclats restés bruts, peu de traces sont visibles et elles sont difficilement interprétables. Il semble qu'ils aient fait l'objet d'une utilisation brève ou sur une matière très tendre. Il faut signaler que cette césure correspond à deux productions distinctes sur le site du Pirou, une importation d'éclats épais et un débitage de petits éclats sur le site.

$\mathrm{Au}$ sein des productions en silex bédoulien chauffé, c'est-à-dire sur le site d'Auriac, on observe une plus grande intensité d'utilisation sur les lamelles que sur les éclats. Pour la production lamellaire, l'intensité d'utilisation ne varie pas en fonction du module (les lamelles sont extrêmement standardisées à Auriac) mais en fonction du code opératoire (tabl. III). Les lamelles les plus utilisées sont dans l'ordre celles à plus de trois négatifs d'enlèvement, celles de

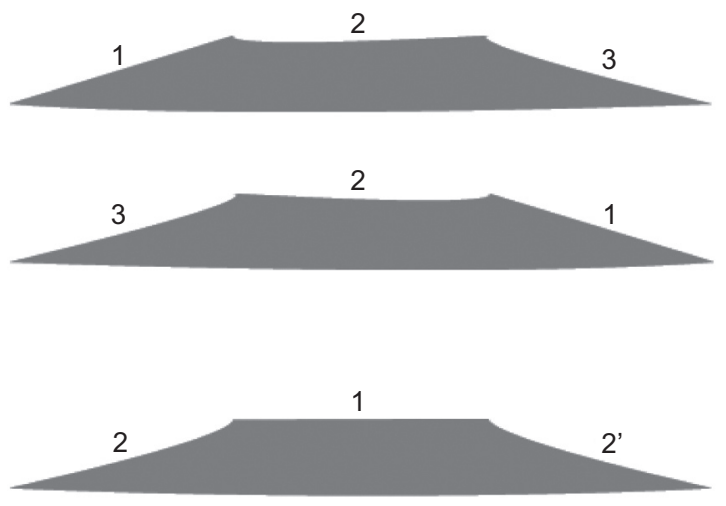

Fig. 43 - Concavités et angles des lamelles de codes opératoires 123/321 et 212' (sections) (DAO: L. Torchy).

code opératoire 212', celles de code opératoire 123/321 et enfin celles de section triangulaire. Concernant les lamelles de section trapézoïdale, la principale motivation dans le choix des lamelles 212' aux dépens des lamelles 123/321 semble être liée à la plus forte régularité des premières. Un autre facteur a pu être pris en considération. En effet, les différents rythmes de débitage génèrent des concavités qui conditionnent les angles des tranchants. De ce fait, deux lamelles, ayant les mêmes largeurs, épaisseurs et positions 
des nervures, n'auront pas les mêmes angulations si leurs codes opératoires sont différents (fig. 43). Ces lamelles, destinées à satisfaire des besoins variés, ont probablement fait l'objet d'une sélection en fonction du pouvoir de coupe et/ ou de la fragilité des bords. L'adaptation de l'angle du bord pour une fonction précise peut être illustrée par l'exemple du recyclage par un coup de burin, entraînant une modification considérable de l'angle du tranchant et le rendant apte pour le raclage des végétaux tendres rigides (Gassin, Léa et al., 2006). L'analyse fonctionnelle d'un échantillon de lamelles plus conséquent croisée avec une étude des propriétés mécaniques des tranchants est en cours afin d'essayer de déterminer l'importance du choix des angles pour les différentes activités.

\section{DIFFÉRENCES DE GESTION ET STATUTS DES SITES}

La plus grande intensité d'utilisation est observée sur le site du Pirou avec une utilisation de $72 \%$ des lames non chauffées et de $34 \%$ des éclats non chauffés. Sur le site de Langel, ces taux sont nettement inférieurs, $44 \%$ pour les lames non chauffées et $22 \%$ pour les éclats non chauffés. Enfin, sur le site d'Auriac le taux d'utilisation des lamelles débitées après chauffe est de $46 \%$. Si ces différences d'intensité d'utilisation sont révélatrices de l'investissement nécessaire pour l'acquisition des supports, l'approvisionnement en silex bédoulien serait moins aisé sur le site du Pirou que sur les deux autres sites.

Concernant les activités réalisées sur les différents sites, on observe une forte similitude entre le site du Pirou et celui de Langel (fig. 44). Sur ces sites, les activités les plus représentées sont la coupe de végétaux et le raclage de la peau. Le travail de l'os et le travail des matières minérales ne sont représentés que sur le site du Pirou. Le raclage de végétaux est présent uniquement à Langel. Les armatures de flèche sont un peu plus représentées à Langel que sur le site du Pirou.

Le spectre fonctionnel d'Auriac diffère radicalement de celui des deux autres sites. L'utilisation des burins pour le raclage de végétaux est relativement bien représentée alors que la coupe de végétaux tendres est anecdotique. Le taux de raclage de la peau est également plus faible que sur les deux autres sites. Le travail sur matières indéterminées représente $60 \%$ sur le site d'Auriac, ce qui peut s'expliquer

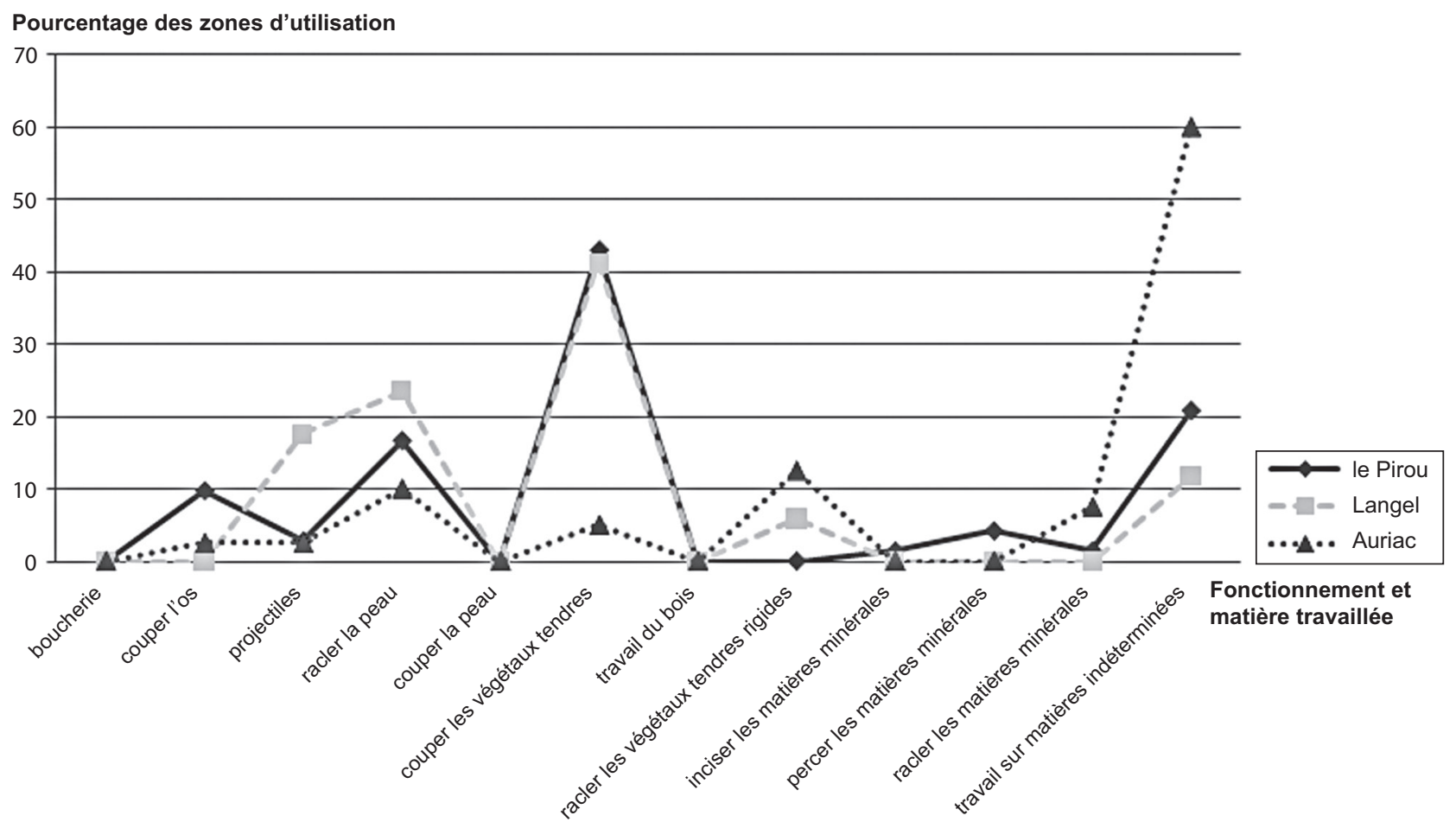

Fig. 44 - Classes fonctionnelles des trois sites étudiés en pourcentage des zones utilisées (DAO: L. Torchy). 
par le fait que les lamelles ont souvent été trop brièvement utilisées, ce qui n'a pas permis d'interprétation fonctionnelle. Les pourcentages indiqués dans ces trois spectres ne révèlent pas directement des proportions absolues attribuables à chaque classe fonctionnelle, mais sont des valeurs relatives qui ont pu être biaisées par la stratégie d'échantillonnage. Toutefois, ces spectres nous donnent une idée des activités principales réalisées sur les trois sites.

Dans une certaine mesure, l'importance de certaines activités et les différences de gestion des productions lithiques peuvent révéler certaines caractéristiques du statut des sites. Lors de l'étude technologique, l'hypothèse d'un site d'habitat à vocation agricole avait été proposée pour le site du Pirou (Torchy, 2008). L'étude tracéologique est en accord avec celle-ci puisque l'activité de coupe de végétaux est majoritairement représentée.

À Langel, l'intensité d'utilisation est plus faible, cela peut s'expliquer par le fait que les produits laminaires représentent près de la moitié du silex bédoulien (Briois, 2005). Ils sont donc plus abondants qu'au Pirou. Langel pourrait être mieux approvisionné. Le spectre fonctionnel est proche de celui du Pirou, ce qui peut indiquer le même statut, c'est-à-dire une vocation agricole.

$\mathrm{Au}$ regard de la proportion de lamelles en silex bédoulien chauffé, de leur forte standardisation et du déficit de nucléus, l'hypothèse d'un statut de site redistributeur de silex bédoulien chauffé a été proposée pour le site d'Auriac (Vaquer, 1991; Vaquer, Remicourt, 2010). Les résultats de l'analyse tracéologique confortent le fait que l'approvisionnement en silex bédoulien chauffé - préformes ou lamelles - fut aisé, puisque les lamelles ont été peu ou brièvement utilisées. Toutefois, la redistribution est moins évidente. Le spectre fonctionnel du site d'Auriac se distingue des deux autres par une quasi-absence de traces de coupe de végétaux tendres. Puisque ce site ne semble pas être à vocation agricole, ce qui est plutôt rare pour un site de plein air chasséen, nous devons nous interroger sur la très forte représentation du travail sur matières indéterminées. Les lamelles, classées dans ce groupe, ont des bords pratiquement intacts et les quelques micro-écaillements observés auraient très bien pu être causés par le transport des produits ou par le piétinement, ce qui s'accorde assez bien avec l'hypothèse d'un passage sur le site avant une éventuelle redistribution vers des sites géographiquement proches d'Auriac mais moins bien intégrés dans les réseaux d'échanges.

\section{VARIABILITÉ GÉOGRAPHIQUE ET CHRONOLOGIQUE}

Afin de tenter de comprendre et de caractériser la gestion des outillages sur les sites languedociens, les résultats de cette étude doivent être comparés avec celles réalisées sur des sites languedociens, mais aussi sur les sites provençaux ou les sites qui se trouvent hors de l'aire d'expansion du Chasséen méridional et qui ont révélé du silex bédoulien.

Sur les Plots à Berriac (Aude), site de plein air attribué au Chasséen ancien et géographiquement proche des sites du Pirou et de Langel, le silex bédoulien, exclusivement non chauffé, est plus intensément utilisé que les silex locaux. La coupe de végétaux est la classe fonctionnelle majoritairement représentée (S. Philibert, cité dans Gassin, 1996), tout comme sur les sites du Pirou et de Langel. À l'inverse, cette classe est peu représentée dans la couche 10 de l'abri sous roche de Font-Juvénal à Conques-sur-Orbiel (Aude), où la fonction dominante des lames en silex bédoulien est le travail de boucherie (Guilaine et al., 1990). Cela révèle des différences d'activités entre des sites contemporains d'une même région. Dans quelle mesure peut-on alors établir un lien de complémentarité entre eux? Comment cela se répercute-t-il sur les réseaux de diffusion du silex bédoulien à une échelle locale? Comment s'organise ce qu'on pourrait qualifier de réseaux secondaires?

À la grotte de Montou à Corbères-les-Cabanes (PyrénéesOrientales), site de culture Monbolo et totalement en aval des chaînes opératoires du silex bédoulien, les lamelles débitées par pression sur silex bédoulien chauffé sont toujours de faible module et les lames en silex bédoulien non chauffé sont toujours très retouchées (communication orale de V. Léa). Les nucléus en silex bédoulien chauffé arrivaient donc sur le site déjà entamés puisque l'on ne retrouve pas les lamelles les plus grandes, probablement débitées ailleurs. Cet indice de débitage intermittent pourrait aussi s'accompagner d'utilisation intermittente des lames en silex bédoulien non chauffé qui sont extrêmement retouchées (Léa, 2005). Qu'en déduire de la diffusion du silex bédoulien à une échelle locale ? Cela passe-t-il par des sites redistributeurs, comme cela pourrait être le cas pour Auriac? En contexte Sepulcros de Fosa (Catalogne), le site de Bòbila Madurell semble avoir une position centrale au sein du territoire local, puisque la plupart des lames sont utilisées brutes avec une intensité d'utilisation plus importante pour les plus larges. Un des sites consommateurs serait 
Camí de Can Grau, où les lames sont souvent retouchées et toutes intensément utilisées (Gibaja Bao, 2003).

Par ailleurs, le site d'Auriac n'est que très peu atteint par les productions laminaires en silex bédoulien non chauffé alors que les lamelles débitées après traitement thermique représentent plus de $90 \%$ de l'industrie lithique. On observe l'inverse sur les sites du Pirou et de Langel, quelques lamelles en silex bédoulien chauffé sont noyées dans les productions en silex bédoulien non chauffé. On peut alors se demander si les productions en silex bédoulien chauffé et non chauffé empruntent les mêmes réseaux de diffusion (Vaquer, Remicourt, 2010).

En amont de ces réseaux, les différentes productions sont parfois réalisées sur différents ateliers. Sur le site des Trois-Termes à Gordes (Vaucluse), des préformes traitées thermiquement sont exportées pour un débitage de lamelles sur sites consommateurs, alors que sur le site de Rocalibert à Piolenc (Vaucluse), des lamelles sont débitées sur place à partir de nucléus chauffés puis exportées sous forme de produits finis (Léa, 2004a). Le déficit de nucléus observé sur le site d'Auriac (Remicourt, 2004) peut s'expliquer de deux manières: soit des préformes traitées thermiquement (provenant d'un site comme celui des TroisTermes) ont été importées, entamées, puis exportées vers d'autres sites consommateurs (comme la grotte de Montou), soit des lamelles issues de nucléus chauffé (débitées sur un site comme celui de Rocalibert) ont été importées sur le site sous forme de produits finis et, peut-être, exportées dans des réseaux secondaires locaux pour certaines d'entre elles. Ces deux modes de diffusion pourraient d'ailleurs se combiner. Quoi qu'il en soit, les schémas témoignent de l'organisation complexe des réseaux de diffusion.

À la grotte de l'Église supérieure à Baudinard (Var), une différence de gestion a été constatée entre les productions sur silex bédoulien chauffé et non chauffé, sur silex oligocène et sur matières premières locales (Gassin, 1996). L'intensité maximale d'utilisation a été observée sur les lames sur silex bédoulien non chauffé, et ensuite par ordre décroissant sur les éclats sur silex bédoulien non chauffé, les lames sur silex oligocène non chauffé, les lamelles sur silex bédoulien chauffé, et enfin, les éclats sur silex locaux. Il y a ici un lien entre l'accessibilité des matières premières et l'intensité d'utilisation, qui est également perceptible sur le site producteur de la Combe à Caromb (Vaucluse) où les lames sont utilisées brutes et avec une faible intensité d'utilisation (Gassin, Léa et al., 2006). Si l'on compare les productions de lames sur silex bédoulien non chauffé de la grotte de l'Église (en moyenne $75 \%$ des pièces sont utilisées), sur le site du Pirou (72\%) et sur le site de Langel (44\%), cela indiquerait que l'approvisionnement serait plus aisé pour le Pirou, et surtout pour le site de Langel alors qu'ils sont géographiquement bien plus loin des sources que la grotte de l'Église. Cette dernière fait peut-être l'objet d'approvisionnements indirects.

Concernant les lamelles sur silex bédoulien chauffé, le pourcentage moyen de pièces utilisées est de $52 \%$ à la grotte de l'Église, avec un minimum de $39 \%$ dans la couche 6 (Gassin, 1996). Un regroupement spatial de lamelles peu ou pas du tout utilisées dans la couche 6 a été constaté; l'hypothèse d'un stock dans lequel on pouvait puiser au fur et à mesure des besoins a été envisagée (Gassin et al., 2010). Sur les sites du Pirou et de Langel, les produits les plus larges ont été plus intensément utilisés, cela pourrait montrer une sélection dans un stock de supports importés.

Si l'on observe les spectres fonctionnels de la grotte de l'Église (fig. 45), l'activité la plus représentée est la boucherie, ainsi qu'une bonne représentation du travail de la peau et du raclage des végétaux tendres. La peau a souvent été raclée avec des bords de lames (Gassin, 1996). Cette fonction n'a pour le moment pas été observée en Languedoc, où la peau a été raclée à l'aide de grattoirs. Le bord d'une lame étant rectiligne, il est plus adapté pour travailler sur une surface convexe, comme un billot de bois, ou plane, tandis que la délinéation convexe du front d'un grattoir en fait un outil plus efficace sur une surface plane ou concave comme une peau tendue sur un cadre. Des traitements différents interviennent-ils dans différentes étapes de la chaîne opératoire du traitement de la peau ? Celle-ci est-elle segmentée dans l'espace et dans le temps avec l'utilisation d'outils différents ? A-t-on affaire ici à des diversités techniques régionales?

Les burins ayant raclé des végétaux sont fréquents dans les assemblages du Chasséen méridional (Gassin, Astruc et al., 2006). Dans d'autres cultures approvisionnées en silex bédoulien, il semble que ces traits techniques ne soient pas empruntés, la pratique du raclage de végétaux est attestée en contexte Monbolo mais pas le façonnage de burins, et en contexte des Sepulcros de Fosa, le raclage des végétaux n'est pas du tout observé. L'utilisation des burins pour racler des végétaux est une tradition culturelle propre au Chasséen méridional, qui n'a pas été adoptée par d'autres groupes récepteurs de silex bédoulien. 


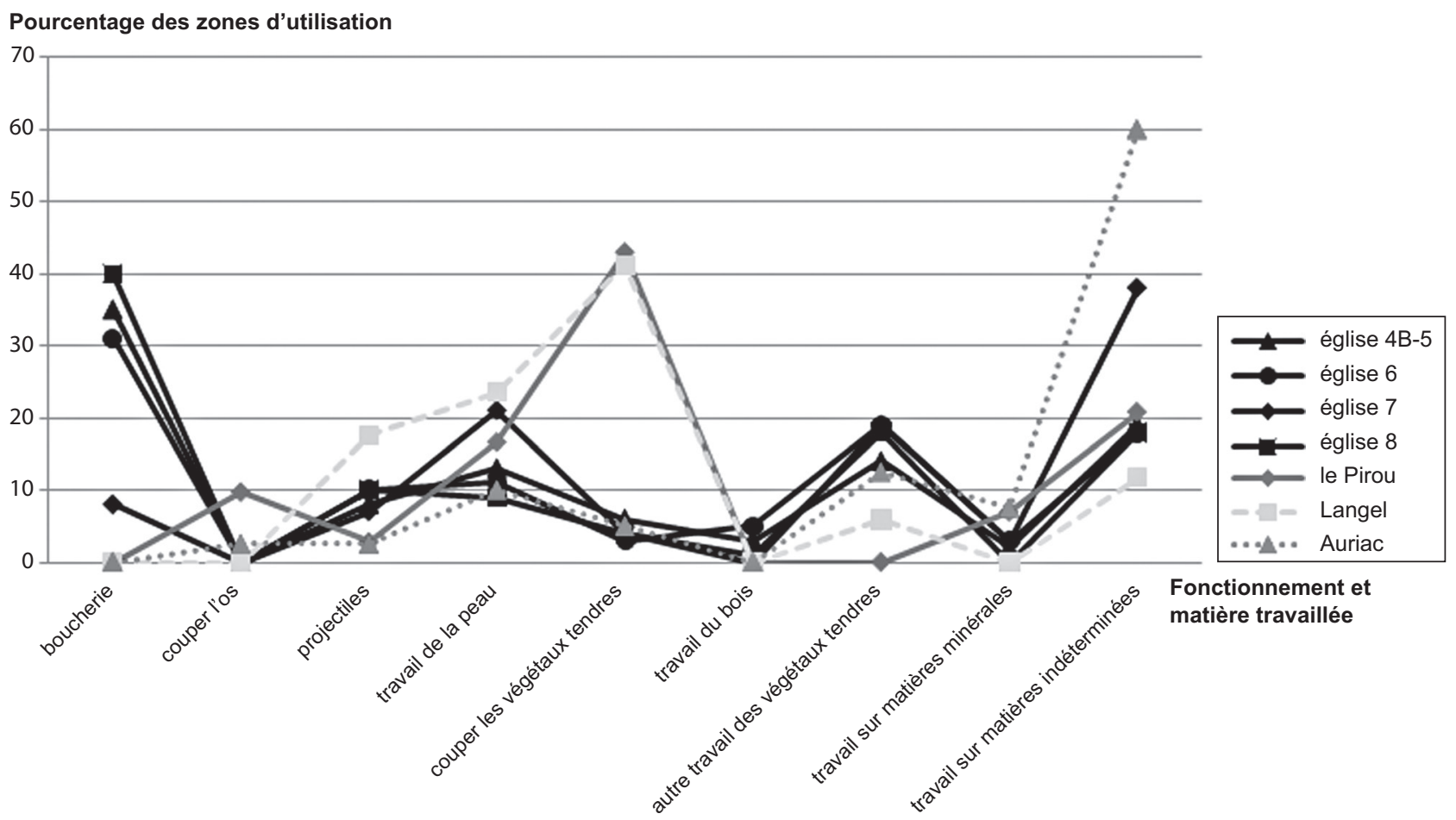

Fig. 45 - Classes fonctionnelles des trois sites languedociens comparées à celles de la grotte de l'Église supérieure (DAO: L. Torchy).

\section{CONCLUSION}

L'étude du fonctionnement des outils a permis d'apporter des informations sur les sous-systèmes techniques dans lesquels ils étaient mis en œuvre. Les lames ayant coupé des végétaux tendres ont été utilisées dans plusieurs conditions. Des lames semblent avoir fonctionné pendant une durée relativement courte, les mêmes traces sont visibles sur les pièces expérimentales ayant coupé des céréales durant moins d'une heure. Le fil actif de ces pièces n'est presque pas émoussé. Dans ce cas, pourquoi les avoir rejetées ? Quelques pistes de réflexion doivent être ouvertes à ce propos.

Nos expérimentations nous ont montré qu'en une heure, il était possible de couper des céréales, sur approximativement une centaine de mètres carrés. Au bout de ce laps de temps, les tranchants sont toujours aussi efficaces, et la coupe de plusieurs dizaines d'ares génère des traces beaucoup plus importantes. Il faut peut-être imaginer les champs néolithiques comme de petites parcelles de quelques centaines de mètres carrés, ce qui entre en contradiction avec l'emploi d'un tribulum qui est utilisé pour des productions beaucoup plus importantes. Les lames ayant coupé des végétaux et présentant des traces de contacts réguliers avec une matière minérale seraient plutôt à mettre en relation avec un équipement léger.

Concernant le raclage de la peau, le fait que l'on n'utilise pas de bord de lame comme en Provence, mais des grattoirs, semble s'expliquer par une diversité culturelle. Il faut toutefois signaler que l'on retrouve surtout les grattoirs dans les assemblages du Chasséen ancien (Léa, 2004b). Il faudrait observer des lames du Chasséen récent pour vérifier si le transfert technique entre la Provence et le Languedoc a eu lieu pendant cette période. Même si cette activité est très représentée, dans quelle mesure peut-on parler de spécialisation artisanale ou de travaux domestiques ? La question se pose aussi pour le travail de l'os et de la céramique sur le site du Pirou.

Même si les disparités d'ordre chronologique font que les productions d'Auriac ne sont pas semblables à celles des deux sites chasséens anciens, des différences de statuts de sites ont pu être mises en évidence grâce à la représentation des classes fonctionnelles. La forte représentation de la coupe de végétaux sur les sites du Pirou et de Langel leur confère une vocation agricole. Le fait que les lamelles soient peu utilisées sur le site d'Auriac, et qu'aucune activité 
artisanale ou agricole ne soit très représentée indiquent un statut autre et vont dans le sens de l'hypothèse du statut de site redistributeur de silex bédoulien chauffé (lamelles et/ ou nucléus entamés) pour Auriac.

Concernant les réseaux, la circulation de gros éclats non chauffés en vue d'un débitage de petits éclats sur sites consommateurs semble introduire ou préfigurer la circulation des préformes chauffées (Torchy, 2008). Cela est perceptible par l'analyse fonctionnelle puisque sur les deux sites attribués au Chasséen ancien (Le Pirou et Langel) les petits éclats débités sur place font l'objet d'une utilisation brève, tout comme les lamelles en silex bédoulien chauffé débitées sur le site du Chasséen classique (Auriac).

Le silex oligocène d'origine provençale est absent des assemblages des trois sites étudiés, et il est par ailleurs très rare en Languedoc (Léa, 2004b). Le fait que ce silex soit principalement diffusé vers l'est indique qu'il s'agit proba- blement de réseaux autonomes qui ne sont pas calqués sur les réseaux du silex bédoulien. Au regard de l'assemblage lithique d'Auriac, il semble d'ailleurs que les productions en silex bédoulien chauffé et les productions en silex bédoulien non chauffé aient été diffusées par des réseaux différents (Vaquer, Remicourt, 2010). D'autres productions circulant sur des longues distances, comme l'obsidienne, paraissent se greffer sur des réseaux déjà en place (Vaquer, 2007).

Les réseaux de diffusion du silex bédoulien ont fait l'objet d'une mise en place progressive, avec probablement le recours à des réseaux secondaires à une échelle locale. Pour chaque matière première, les productions diffusées ne sont pas toujours calquées sur les mêmes schémas géographiques et révèlent certainement des réseaux différents. Ainsi l'étude techno-fonctionnelle que nous avons menée permet d'approcher la complexité de l'organisation territoriale des sociétés chasséennes. 


\title{
BIBLIOGRAPHIE
}

\author{
AbRéviations \\ APDCA Association pour la promotion et la diffusion des connaissances archéologiques. \\ APRAIF Association pour la promotion de la recherche en Île-de-France. \\ BAR British Archaelogical Reports. \\ CTHS Comité des travaux historiques et scientifiques. \\ SPF Société préhistorique française.
}

\section{Anderson P., CHABot J.}

2004: «La première machine agricole et les lames cananéennes", Les Dossiers de l'archéologie: la tribologie, 290, p. 44-51.

Anderson P., Chabot J., Van Gijn A. 2004: "The functional Riddle of "Glossy" Canaanean Blades and the Near Eastern Threshing Sledge", Journal of Mediterranean Archaeology, 17, 1, p. 87-130.

\section{ANDERSON P., GEORGES J.-M.,}

VARGIOLU R., ZAHOUANI H.

2006: «Insights from a tribological analysis of the tribulum ", Journal of Archaeological Science, 33, p. 1559-1568.

\section{ASTRUC L., LÉA V.}

À paraître: «Les cycles d'utilisation des lame(lle)s en silex bédouliens à Montou: rythmes d'occupation et mobilité", in Claustre F., La Grotte de Montou (Pyrénées-Orientales): études chronostratigraphique, environnementale et fonctionnelle.

\section{BINDER D.}

1984: «Systèmes de débitage laminaire par pression : exemples chasséens provençaux", in TIXIER J., INIZAN M.-L., ROCHE H. (DIR.), Préhistoire de la pierre taillée -2- Économie du débitage laminaire, Paris, Cercle de recherches et d'études préhistoriques, p. 71-84.

1991: «Facteurs de variabilité des outillages lithiques chasséens dans le sud-est de la France», in BEECHING A., BINDER D., BLANCHET J.-C. (DIR.), Identité du Chasséen, Actes du colloque international de Nemours, 17-19 mai 1989, Nemours, APRAIF (coll. Mémoires du musée de Préhistoire d'îlede-France, 4), p. 261-272.

\section{BINDER D., GASSIN B.}

1988: «Le débitage laminaire chasséen après chauffe: technologie et traces d'utilisation", in BEYRIES S., Industries lithiques, tracéologie et technologie, Oxford,
Archaeopress (coll. BAR International Series, 411), p. 93-125.

\section{BINDER D., PERLÈs C., INIZAN M.-L., LECHEVALLIER M.}

1990: «Stratégies de gestion des outillages lithiques au Néolithique», Paléo, 2, p. $257-283$

\section{BRIOIS F.}

2005: Les Industries de pierre taillée néolithiques en Languedoc occidental: nature et évolution des outillages entre les $\mathrm{VI}^{e}$ et $\mathrm{III}^{e}$ millénaires av. J.-C., Lattes, Association pour le développement de l'archéologie en Languedoc-Roussillon (coll. Monographies d'archéologie méditerranéenne, 20), $341 \mathrm{p}$.

Claud E.

2008: Le Statut fonctionnel des bifaces au Paléolithique moyen récent dans le sud-ouest de la France: étude tracéologique intégrée des outillages des sites de la Graulet, le Conne de Bergerac, Combe Brune 2, Fonseigner et Chez-Pinaud / Jonzac, Thèse de Doctorat, Université de Bordeaux-I, 546 p.

\section{GAILlaRd A.}

1998: L'Outillage osseux du site chasséen méridional classique d'Auriac, Carcassonne (Aude), Toulouse, Mémoire de diplôme de l'EHESS sous la direction de J. Guilaine, $180 \mathrm{p}$.

\section{GASSIN B.}

1996: Évolution socio-économique dans le Chasséen de la grotte de l'Église supérieure (Var): l'apport de l'analyse fonctionnelle des industries lithiques, Paris, CNRS Éditions (coll. Monographie du CRA), 17, 327 p.

GaSSin B., ASTRUC L., LÉa V., Philibert S., Gibaja BaO J. F.

2006: «Burins du Chasséen méridional», ArchéoLogiques, 2, p. 319-341.
GaSSin B., LÉa V., ASTruc L., Linton J. 2010: «Lithic Management in the Chassey Culture Neolithic", Human Evolution, 25, 1-2, p. 125-142.

Gassin B., LÉa V., Linton J., ASTruC L. 2006: «Production, gestion et utilisation des outillages lithiques du Chasséen méridional», in AsTruC L., BON F., LÉA V., MILCENT P.-Y. (DIR.), Normes techniques et pratiques sociales: de la simplicité des outillages pré- et protohistoriques, $\mathrm{XXVI^{e }}$ rencontres internationales d'archéologie et d'histoire d'Antibes, Antibes, APDCA, p. 223-233.

\section{GIBAJA BAO J. F.}

2003: Neolíticas del Noreste de la Península Ibérica : Una aproximación socio-económica a partir del estudio de la función de los útiles líticos, Oxford, Archaeopress (coll. BAR International Series, 1140), $318 \mathrm{p}$

GONZÁLEZ URQUiJo J. E., IBÁÑEZ ESTEVEZ J. J.

1994: Metodología de análisis funcional de instrumentos tallados en sílex, Bilbao, Universitad de Deusto, Departamento de Publicaciones, $302 \mathrm{p}$.

\section{GuILAINE J.}

1970: «Recherches de Préhistoire récente en Languedoc occidental et Roussillon: campagne de recherches 1969», Cahiers ligures de Préhistoire et d'archéologie, 19, p. $149-174$.

\section{Guilaine J., Amiel C., Barthès P.,} Coularou J., VAQUer J.

1990: «Le Chasséen de l'abri de FontJuvénal», in Guilaine J., GUTHERZ X. (DIR.), Autour de Jean Arnal: recherches sur les premières communautés paysannes en Méditerranée occidentale, Montpellier, Laboratoire de paléobotanique, p. 163176. 
Ibáñez Estevez J. J., Clemente Conte I., GaSSin B., Gibaja BAO J. F., GoNZÁlez URQUiJo J. E., MARQUEZ B. PHILIBERT S., RODRIGUEZ RODRIGUEZ A.

2008: "Harvesting technology during the Neolithic in South-West Europe», in LONGO L., SKAKUN N. (DIR.), "Prehistoric Technology": 40 years later, Oxford, Archaeopress (coll. BAR International Series, 1783), p. 183-195.

\section{JÉDIKIAN G.}

1998: Typologie et statistique de la céramique chasséenne: le cas d'Auriac (Carcassonne, Aude), Toulouse, Mémoire de diplôme de l'EHESS sous la direction de J. Guilaine, $156 \mathrm{p}$.

\section{KOTARBA J.}

1998: A75, section Béziers-Pézenas: prospections archéologiques -2- Présentation de l'opération et synthèse, SRA Languedoc-Roussillon / AFAN / DDE de l'Hérault, 99 p., 35 fig., 11 tabl.

\section{Kotarba J., DURAND G., Guerre J.,} LOISON G., MAZIÈRE F., PRÊT S., RASCALOU P.

1998: A75, section Béziers-Pézenas: prospections archéologiques -3-Catalogues des sites, SRA Languedoc-Roussillon / AFAN / DDE de l'Hérault, volume non paginé, 31 fig.

LÉA V. avec la collab. de BINDER D., Bouby L., Buisson-Catil J., CARry A., Castan m., Convertini F., Devalque C., GASSIN B., GEORJON C., GERNIGON K., GRENET M., LEPÈRE C., RENAULT S., SÉNÉPART I., THIRAULT E., VERdiN P.

2003: Sites producteurs et sites consommateurs durant le Chasséen en Vaucluse: gestion des silex bédouliens, périodisation chronoculturelle, PCR 2003-2005, Aix-enProvence, $78 \mathrm{p}$.

2004a: "Centres de production et diffusion des silex bédouliens au Chasséen » Gallia Préhistoire, 46, Paris, CNRS Éditions, p. 231-250.

2004b: Les Industries lithiques du Chasséen en Languedoc oriental: caractérisation par l'analyse technologique, Oxford, Archaeopress (coll. BAR International Series, 1232), 215 p.

2004c: «Les productions sur galets locaux du Néolithique moyen du sud de la France», in DARTEVELle H. (DIR.), Auvergne et Midi, $V^{T}$ rencontres méridionales de Préhistoire récente, Clermont-Ferrand, 8-9 nov. 2002, Cressensac, Préhistoire du SudOuest (Suppl. à Préhistoire du Sud-Ouest, 9), p. 395-403.
2005: «Raw, Pre-heated or Ready to Use: Discovering Specialist Supply Systems for Flint Industries in Mid-Neolithic (Chassey culture) Communities in Southern France", Antiquity, 79, 303, p. 51-65.

2007: «Étude technologique de l'industrie lithique " in Daveau I. (DIR.), Port Ariane (Lattes, Hérault): construction deltaïque et utilisation d'une zone humide lors des six derniers millénaires, Lattes (coll. Lattara, 20), p. 343-353.

LÉA V., BINDER D., BRIOIS F., VAQUER J. 2007: "Le Chasséen méridional à lamelle" d'Arnal: évolution de notre perception des industries lithiques", in ÉVIN J. (DIR.), Un siècle de construction du discours scientifique en Préhistoire: des idées d'hier aux conceptions d'aujourd'hui, Actes du XXVI congrès préhistorique de France, congrès du centenaire de la SPF, Avignon, 21-25 sept. 2004, Paris, SPF, vol. 3, p. 263-275.

\section{LÉA V., GASSIN B., BRIOIS F.}

2004: «Fonctionnement des réseaux de diffusion des silex bédouliens du $\mathrm{V}^{\mathrm{e}}$ au IV ${ }^{\mathrm{e}}$ millénaire: questions ouvertes», in DARTEVElle H. (DIR.), Auvergne et Midi, $V^{e}$ rencontres méridionales de Préhistoire récente, Clermont-Ferrand, 8-9 nov. 2002, Cressensac, Préhistoire du Sud-Ouest (Suppl. à Préhistoire du Sud-Ouest, 9), p. $405-420$.

\section{MÉNARD C.}

2008: Étude technologique des grattoirs lithiques d'une occupation moderne éthiopienne, Eth73-3-II, Macho Hill, ethnoarchéologie d'un procédé d'emmanchement, Mémoire de Master 2 sous la direction de M. Barbaza, Université de Toulouse-Le Mirail.

\section{PERLÈs C.}

2007: «Échanges et technologie: l'exemple du Néolithique», in ÉVIN J. (DIR.), Un siècle de construction du discours scientifique en Préhistoire: des idées d'hier aux conceptions d'aujourd'hui, Actes du XXVI congrès préhistorique de France, congrès du centenaire de la SPF, Avignon, 21-25 sept. 2004, Paris, SPF, vol. 3, p. 53-62.

\section{PLISSON H.}

1985: Étude fonctionnelle des outillages lithiques préhistoriques par l'analyse des micro-usures: recherche méthodologique et archéologique, Thèse de $3^{\text {e }}$ cycle, Paris, Université de Paris-I-Panthéon-Sorbonne, $357 \mathrm{p}$.

1986: «Altération des micropolis d'usage: quelques expériences complémentaires », in OWEN L., UNRATH G. (DIR.), Technical aspects of micro-wear studies on stone tools, Tübingen, Archeologica Venatoria, p. 111-116.

\section{Plisson H., MAUger M.}

1988: «Chemical and mechanical alteration of microwear polishes: an experimental approach », Helinium, 28, 1, p. 3-16.

\section{REMICOURT M.}

2004: Techniques et variabilités des industries lithiques chasséennes: le cas d'Auriac (Carcassonne, Aude), Toulouse, Mémoire de DEA sous la direction de J. Vaquer, $133 \mathrm{p}$.

\section{RENFREW C.}

1984: Approaches to social archaeology, Harvard, Harvard University Press, $430 \mathrm{p}$.

\section{ROTS V.}

2008: «Hafting traces on flint tools», in LONGO L., SKAKUN N. (DIR.), "Prehistoric Technology": 40 years later, Oxford, Archaeopress (coll. BAR International Series, 1783), p. 75-84.

\section{SERRES C.}

1950: "Commune de Valros et limitrophes", Bulletin de la société archéologique de Béziers, 16, p. 4-9.

\section{TORCHY L.}

2008: Contribution à l'étude des sites de plein air chasséens du Languedoc: approche technologique de l'assemblage lithique du Pirou (Valros, Hérault), Mémoire de Master 1 sous la direction de V. Léa, Université de Toulouse-Le Mirail, 126 p.

2009: Gestion des outillages en silex bédoulien sur les sites consommateurs chasséens $d u$ Languedoc: approche tracéologique des industries du Pirou, de Langel et d'Auriac, Mémoire de Master 2 sous la direction de J. Vaquer, Université de Toulouse-Le Mirail, 42 p.

\section{TORChY L., GASSIN B.}

2010: «Le travail de la poterie en contexte chasséen: des outils en silex pour la production céramique ?", in Actes de la séance de la SPF du 17 mars 2010, Nanterre, Bulletin de la $S P F, 107,4$, p. 725-735.

\section{VAQUER J.}

1990: Le Néolithique en Languedoc occidental, Paris, CNRS Éditions, 398 p.

1991: «Aspects du Chasséen en Languedoc occidental », in BEECHING A., BINDER D., BLANCHET J.-C. (DIR.), Identité $d u$ Chasséen, Actes du colloque international de Nemours, 17-19 mai 1989, Nemours, 
APRAIF (coll. Mémoires du musée de Préhistoire d'Île-de-France, 4), p. 27-37. 2007: «Le rôle de la zone nord-tyrrhénienne dans la diffusion de l'obsidienne en Méditerranée nord-occidentale au Néolithique ", in D'ANNA A., CESARI J., OGEL L., VAQUER J. (DIR.), Corse et Sardaigne préhistoriques: relations et échanges dans le contexte méditerranéen, Actes du $128^{e}$ congrès national des sociétés historiques et scientifiques, section de Pré- et Protohistoire, 2003, Bastia, éd. du CTHS, p. 99-120.

\section{VAQUer J., REMicourt M.}

2010: "Rythmes et modalités d'approvisionnement en silex blond bédoulien dans le Chasséen du bassin de l'Aude: le cas d'Auriac, Carcassonne (Aude)", in Beeching A., Thirault E., Vital J. (DIR.), Économie et société à la fin de la Préhistoire, Actualité de la recherche, Actes des VII rencontres méridionales de Préhistoire récente, Lyon, 3-4 nov. 2006, Lyon, ALPARA (coll. DARA, 34), p. 39-56. 